\title{
Partial Orders and Euclidean Geometry
}

\author{
JORGE URRUTIA
}

Department of Computer Science, University of Ottawa, Ottawa, Ontario, Canada. 


\section{INTRODUCTION}

The study of simple families of geometric objects on the plane has always been of great interest in mathematics. Incidence relations among families of points, lines and circles on the Euclidean plane were studied intensely long ago. In fact, most of what is now considered as basic Euclidean Geometry was developed a few centuries before the advent of the Christian Era. The Books of Euclid are an impressive product of the advances achieved in geometry in the early days of mathematics. In those days, special emphasis was paid to constructions realizable with a ruler and a compass. Three famous problems that interested the Greek mathematicians were the trisection of an angle, squaring the circle and the duplication of the cube. As we all know, solution of these problems using a ruler and a compass was proved to be impossible in the nineteenth century.

With the advent of combinatorics, a new breed of results in Euclidean Geometry has resulted. This resulted in the development of a new area of mathematics known as Combinatorial Geometry. Two good examples of typical results in this area are the following well-known results: Let $X$ be a finite set of points on the plane. If in the line determined by any two elements of $\mathrm{X}$ there is always a third point in $\mathrm{X}$, then all elements of $\mathrm{X}$ are collinear. The corresponding version of this problem for circles reads as follows: Let $\mathrm{X}$ be a finite set of non collinear points on the plane. If on the circle determined by any three points of $\mathrm{X}$ there is always a fourth point of $\mathrm{X}$, then all elements of $\mathrm{X}$ lie on a circle.

An excellent account of results in combinatorial geometry can be found in Hadwiger, Debrunner and Klee's book Combinatorial Geometry in the Plane [20].

In this paper, we study a different aspect of Euclidean geometry, namely containment relations arising from families of points, circles, triangles, squares, etc.

Let $\square=\left\{S_{1}, \ldots, S_{n}\right\}$ be a family of sets on the plane. We say that $S_{i}$ fits in $S_{j}$ if there exists a rotation, translation and a reflection that maps $S_{i}$ inside $S_{j}$. A partial order $\mathrm{P}(\mathrm{X},<)$ on $\mathrm{X}=\left\{\mathrm{x}_{1}, \ldots, \mathrm{x}_{\mathrm{n}}\right\}$ represents $\square$ if for any $\mathrm{x}_{\mathrm{i}}, \mathrm{x}_{\mathrm{j}} \square \mathrm{X} \mathrm{x}_{\mathrm{i}}<\mathrm{x}_{\mathrm{j}}$ iff $\mathrm{S}_{\mathrm{i}}$ fits in $\mathrm{S}_{\mathrm{j}}$. Our problem in this case is the following one: Given a family $\square=\left\{R_{1}, \ldots, R_{n}\right\}$ of rectangles determine, if possible, a set of parameters $P_{1}, \ldots, P_{m}$ such that rectangle $R_{i}$ fits in rectangle $R_{j}$ if and only if $\mathrm{P}_{1}\left(\mathrm{R}_{\mathrm{i}}\right) \leq \mathrm{P}_{1}\left(\mathrm{R}_{\mathrm{j}}\right), \ldots, \mathrm{P}_{\mathrm{m}}\left(\mathrm{R}_{\mathrm{i}}\right) \leq \mathrm{P}_{\mathrm{m}}\left(\mathrm{R}_{\mathrm{j}}\right)$. Natural candidates for these parameters could be the area, perimeter, etc. of a rectangle. The main objective of Section 2 is to show that the containment problem for rectangles (and thus for polygons with $\mathrm{d} \geq 4$ sides) can not be solved by reducing it 
to a vector dominance problem regardless of the choice and of the finite number of parameters .

A different approach to the study of containment problems can be taken. For instance let $\square=\left\{\mathrm{C}_{1}, \ldots, \mathrm{C}_{\mathrm{n}}\right\}$ be a collection of circles on the plane. A partial order $\mathrm{P}(\mathrm{X},<)$ on $\mathrm{X}=\left\{\mathrm{x}_{1}, \ldots, \mathrm{X}_{\mathrm{n}}\right\}$ represents $\square$ if for any $x_{i}, x_{j} \square X x_{i}<x_{j}$ iff $C_{i}$ is contained in $C_{j} . P(X,<)$ is called a circle order. Some interesting questions arise: What partial orders are circle orders? Is there any geometric property of circles useful to prove that a given partial order is not a circle order? For example, we know that two different circles intersect in at most two points. Is there a parameter which we can associate with a partial order to "measure" this property of circles? Similar questions can be asked for partial orders representing families of triangles, squares, etc. This problem is studied in Section 3.

In Section 4, we study containment relations among sets of points and circles. Our aim in this section is to prove the following result: Let $\mathrm{P}_{n}$ be a collection of points on the plane. For every pair of points $\mathrm{u}, \mathrm{v}$ in $\mathrm{P}_{\mathrm{n}}$ let $\mathrm{C}(\mathrm{u}, \mathrm{v})$ be the minimum number of elements of $\mathrm{P}_{\mathrm{n}}$ contained in any circle containing $\mathrm{u}$ and $\mathrm{v}$. Then there exists a constant $\mathrm{c}>0$ such that the average value of $\mathrm{C}(\mathrm{u}, \mathrm{v})$ over all pairs $\mathrm{u}, \mathrm{v} \square \mathrm{P}_{\mathrm{n}}$ is at least $\mathrm{cn}$. Some related problems are also studied. In particular, we conjecture that in a way this result is a characterization of the circle.We then generalize the results on points and circles to spheres and points in higher dimensions.

Finally in Section 5 we give two characterizations of the circle which were motivated by the results obtained in this paper.

\section{CONTAINMENT PROBLEMS OF MOVABLE OBJECTS ON THE PLANE}

When dealing with sets of simple figures, a basic problem is the determination of containment relations between elements of the set. Given a family $\square$ of geometric figures, the containment problem for $\square$ is the problem of determining for all $\mathrm{A}, \mathrm{B} \square \square$ whether $\mathrm{A}$ can be contained in $\mathrm{B}$; that is, whether there exists a rotation, a translation and a reflection that maps $\mathrm{A}$ into $\mathrm{B}$.

For some families $\square$ of figures, the containment problem can be easily reduced to a problem of vector dominance. For example, $f(\mathrm{~A})$, defined as the area of A, will work for the family $\boldsymbol{P}_{k}$ of regular polygons with $\mathrm{k} \geq 3$ sides, as well as for the family $\boldsymbol{C}$ of circles. A more interesting example is the family $\boldsymbol{E}$ of ellipses; for each $\mathrm{E}_{\mathrm{i}} \square \boldsymbol{E}$, define $f\left(\mathrm{E}_{\mathrm{i}}\right)=\left(\mathrm{x}_{\mathrm{i}}, \mathrm{y}_{\mathrm{i}}\right)$ where $\mathrm{x}_{\mathrm{i}}$ and $\mathrm{y}_{\mathrm{i}}$ 
denote the length of the minor and major axis of $E_{i}$, respectively. It is easy to show that $E_{i}$ can be contained in $\mathrm{E}_{\mathrm{k}}$ if and only if $f\left(\mathrm{E}_{\mathrm{i}}\right) \leq f\left(\mathrm{E}_{\mathrm{k}}\right)$. Similarly, two parameters (namely the lengths of the diagonals) also suffice for rhombi.

It is thus natural to ask, for a given family $\square$ of geometric figures, which function $f: \square \square \mathbb{R}^{n}$ (if any) would reduce the containment problem in $\square$ to vector dominance (i.e., find a mapping $f: \square \square \mathbb{R}^{\mathrm{n}}$ such that $f(\mathrm{~A}) \leq f(\mathrm{~B})$ if and only if A can be contained in B). From a computational point of view, reductions to vector dominance are desirable due to the existence of efficient tools to solve vector dominance problems (e.g., see [7, 10, 23, 24, 25, 26, 28, 29, 41]).

Furthermore, since the complexity of vector dominance algorithms is a function of the dimension of the vectors, it is desirable to determine a $f: \square \square \mathbb{R}^{\mathrm{n}}$ where $\mathrm{n}$ is as small as possible.

Consider the family $\square$ of plane rectangles. In this case, the above question becomes: Is it possible to characterize each rectangle $\mathrm{R}_{\mathrm{i}}$ by an $\mathrm{n}$-vector $\boldsymbol{f}\left(\mathrm{R}_{\mathrm{i}}\right)=\left(f_{1}\left(\mathrm{R}_{\mathrm{i}}\right), \ldots, f_{\mathrm{n}}\left(\mathrm{R}_{\mathrm{i}}\right)\right)$ in such a way that $R_{i}$ can be immersed in $R_{j}$ if and only if $f_{k}\left(R_{i}\right) \leq f_{k}\left(R_{j}\right)$ for $k=1, \ldots, n$ ? Natural candidates for our parametric functions $f_{k}\left(R_{i}\right)$ are the length, width, area, diagonal, perimeter, etc. of $\mathrm{R}_{\mathrm{i}}$. The educated guess that any two of them suffice is, unfortunately, incorrect. For any choice of these functions, a counter-example can be found.

In [34], it was proved by using analytical tools that two parameters are not sufficient to solve this problem. A different way in which we can prove that two parameters do not suffice to solve the containment problem for rectangles is as follows: The existence of 2 parameters ( $\mathrm{k}$ parameters) to solve the containment problem for rectangles implies that the dimension of any finite partial order obtained from a family of rectangles (under containment) is at most 2 ( $\mathrm{k}$ respectively) [for a definition of the dimension of a partial order, see Section 3 of this paper]. The reader can verify for himself that there are six rectangles $R_{1}, \ldots, R_{6}$ such that the partial order generated by them is the partial order $\mathrm{H}_{3}$ shown in Figure 1. However it is a well known fact that $\mathrm{H}_{3}$ has dimension 3 . 


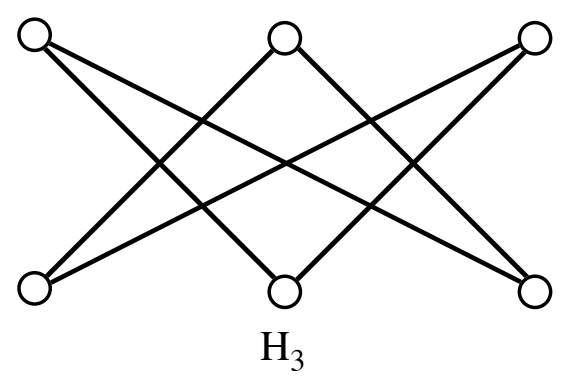

Figure 2.1

Our main objective in the rest of this section is to show that the containment problem for rectangles (and, thus, for polygons with $\mathrm{d} \geq 4$ sides) can not be solved by reducing it to a vector dominance problem regardless of the choice and of the finite number of parameters $\mathrm{f}_{\mathrm{k}}$. On the other hand, it is shown that the reduction for rectangles is possible if a countable number of parameters are used. These results were proved in [34].

\subsection{Geometry of Plane Rectangles}

Given a rectangle $R_{i}$, denote by $a_{i}$ and $b_{i}$ the width and the length of $R_{i}$, respectively. Unless otherwise stated, assume $0 \leq \mathrm{a}_{\mathrm{i}} \leq \mathrm{b}_{\mathrm{i}}$.

There is an obvious one-to-one correspondence between the set $\boldsymbol{R}$ of all rectangles and points $(\mathrm{x}, \mathrm{y})$ in $\mathbf{P}=\{(\mathrm{x}, \mathrm{y}): 0 \leq \mathrm{x} \leq \mathrm{y}\}$. Using this correspondence, associate with each $\mathrm{R}_{\mathrm{i}}$ a region $\mathrm{S}\left(\mathrm{R}_{\mathrm{i}}\right)$ consisting of all points $(\mathrm{x}, \mathrm{y}) \square \mathbf{P}$ representing rectangles that fit in $\mathrm{R}_{\mathrm{i}}$ (see Figure 2.2); in the following, the notations $\left(\mathrm{a}_{\mathrm{i}}, \mathrm{b}_{\mathrm{i}}\right)$ and $\mathrm{R}_{\mathrm{i}}$ will be used interchangeably.

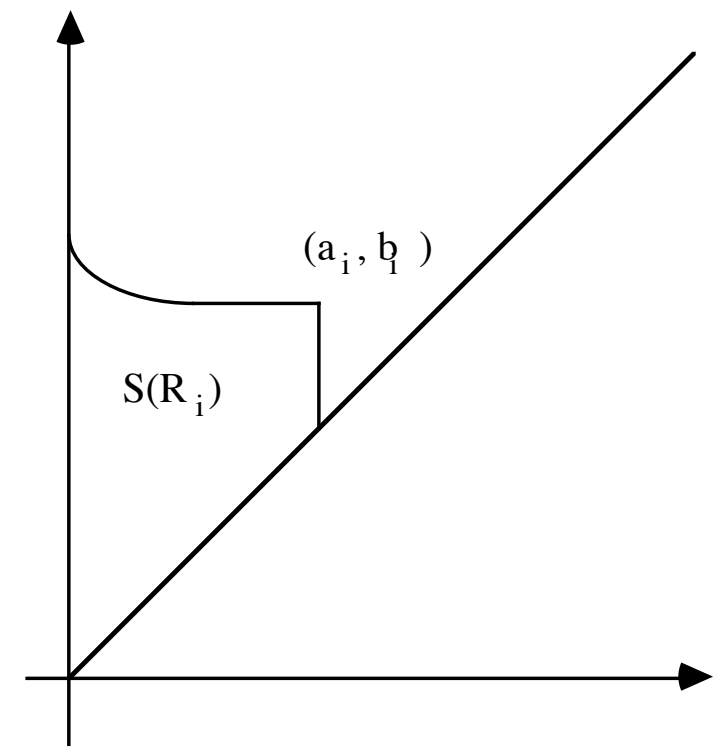

Figure 2.2

Given two rectangles $\mathrm{R}_{\mathrm{i}}, \mathrm{R}_{\mathrm{j}} \square \boldsymbol{R}, \quad \mathrm{R}_{\mathrm{i}}$ is said to fit in $\mathrm{R}_{\mathrm{j}}$ if there exists a rotation and a 
translation that immerses $R_{i}$ in $R_{j}$, and to fit tightly in $R_{j}$ if there does not exist any rectangle $R_{k}\left(R_{j} \neq R_{k} \neq R_{i}\right)$ such that $R_{i}$ fits in $R_{k}$ and $R_{k}$ fits in $R_{j}$.

From the definition of fit and tight fit, the following properties trivially follow:

Lemma 2.1: If $R_{i}$ fits in $R_{j}$ then

(i) $\mathrm{a}_{\mathrm{i}} \leq \mathrm{a}_{\mathrm{j}}$;

(ii)there is a concentric immersion of $R_{i}$ in $R_{j}$.

Lemma 2.2: If $R_{i}$ fits tightly in $R_{j}, R_{i} \neq R_{j}$, then

(i) $b_{i}>b_{j}$;

(ii)in any immersion of $R_{i}$ in $R_{j}$, the vertices of $R_{i}$ lie on distinct sides of $R_{j}$.

Given a square $\mathrm{C}=(\mathrm{u}, \mathrm{u})$, define $\partial(\mathrm{a}, \mathrm{u})$ to be the largest length among the rectangles of width a which fit in $\mathrm{C}$. The following result can be easily proved:

Lemma 2.3: $\partial(a, u)=\operatorname{Max}\{\sqrt{ } 2 l-a, u\}$ for $0 \leq a \leq u$.

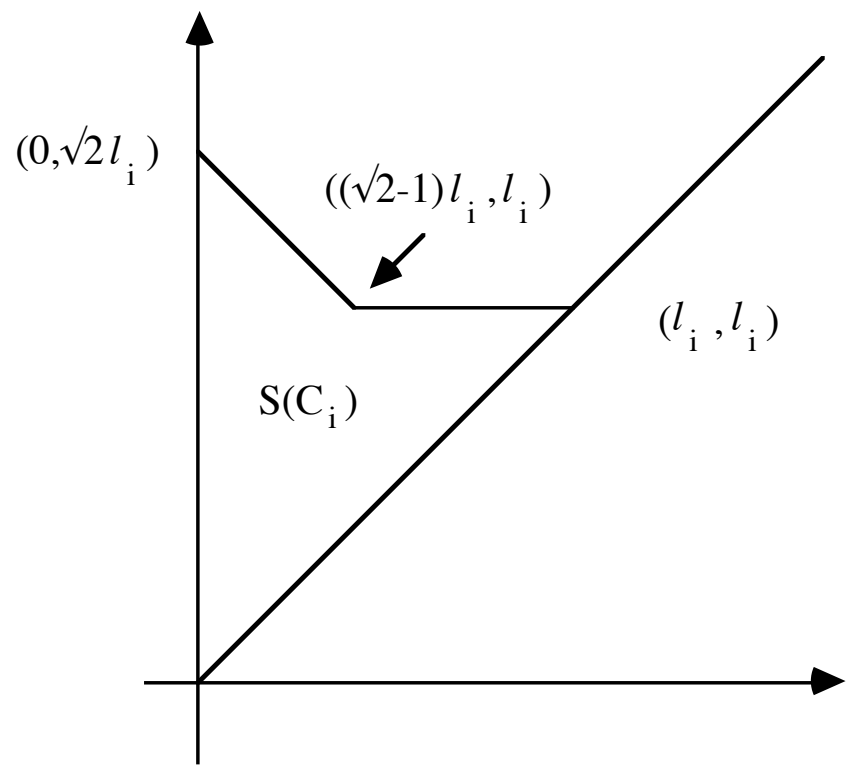

Figure 2.3

The curve in $\mathbf{P}$ defined by $\partial(\mathrm{a}, l)$ for $\mathrm{a} \leq l$, is called the containment curve of $\mathrm{C}=(\mathrm{u}, \mathrm{u})$. From the previous result, it follows that the region $\mathrm{S}(\mathrm{C})$ has the shape illustrated in Figure 2.3. The 
line segment $\mathrm{L}$ joining the points $(0, \sqrt{ } 2 \mathrm{u})$ up to and excluding $((\sqrt{ } 2-1) \mathrm{u}, \mathrm{u})$ corresponds to the rectangles $R(a, \partial(a, 1))$ that fit tightly in $C$, and the line segment $B$ joining $((\sqrt{ } 2-1) u, u)$ to $(\mathrm{u}, \mathrm{u})$ represents the other rectangles $\mathrm{R}(\mathrm{a}, \partial(\mathrm{a}, \mathrm{u}))$. The next result now follows:

Lemma 2.4: If $R_{j}=\left(a_{j}, b_{j}\right) \square L$ and $R_{k}=\left(a_{k}, b_{k}\right) \square B$, then neither $R_{j}$ fits in $R_{k}$ nor $R_{k}$ fits in $\mathrm{R}_{\mathrm{j}}$

\subsection{The Proof of the Rectangle Theorem}

Let $f: N \square \mathbb{R}$ be a real function whose domain is an open convex set $N$ on the plane. Assume that $f$ is monotonically non-decreasing in both coordinates, i.e. $(\mathrm{x}, \mathrm{y}) \leq(\mathrm{w}, \mathrm{z})$ implies that $f(\mathrm{x}, \mathrm{y})$ $\leq f(\mathrm{w}, \mathrm{z})$. Let $\mathrm{g}(\mathrm{u})=\mathbf{a u}+\mathbf{b}$ be a line that intersects $N$, where $\mathbf{a}=\left(\mathrm{a}_{1}, \mathrm{a}_{2}\right), \mathbf{b}=\left(\mathrm{b}_{1}, \mathrm{~b}_{2}\right),\{\mathbf{a}, \mathbf{b}\} \square \mathbb{R}^{2}$, $a_{1}, a_{2} \geq 0$. The following result can be easily proved:

Lemma 2.6: $f$ is continuous almost everywhere in the intersection of $\mathrm{g}(\mathrm{u})$ with $N$.

For a definition of continuity almost everywhere, the reader can consult [30]. We can now proceed with the proof of the rectangle theorem.

Theorem 2.1[34]: The containment problem for rectangles can not be reduced to a vector dominance relation in $\mathbb{R}^{\mathrm{d}}$ regardless of the value of $\mathrm{d}$.

Proof: By contradiction, assume that there is a function $\boldsymbol{f}: \boldsymbol{R} \square \mathbb{R}^{\mathrm{d}}$ such that $\boldsymbol{f}\left(\mathrm{R}_{\mathrm{j}}\right) \leq \boldsymbol{f}\left(\mathrm{R}_{\mathrm{k}}\right)$ if and only if $R_{j}$ fits in $R_{k}$. Then there are $d$ functions $f_{i}: \mathbf{R} \varnothing \mathbb{R}$ (the components of $f$ ) such that $f_{\mathrm{i}}\left(\mathrm{R}_{\mathrm{j}}\right) \leq f_{\mathrm{i}}\left(\mathrm{R}_{\mathrm{k}}\right)$ if and only if $\mathrm{R}_{\mathrm{j}}$ fits in $\mathrm{R}_{\mathrm{k}}, \mathrm{i}=1, \ldots, \mathrm{d}$. Extend $\boldsymbol{f}$ to the whole positive quadrant by setting $\boldsymbol{f}(\mathrm{a}, \mathrm{b})=\boldsymbol{f}(\mathrm{b}, \mathrm{a})$ for $\mathrm{a}>\mathrm{b}$. Consider the two lines $\square=\{((\sqrt{ } 2-1) \mathrm{u}, \mathrm{u}): \mathrm{u} \geq 0\}$ and $\square=\{(\mathrm{u}, \mathrm{u})$ : $\mathrm{u} \geq 0$ \}. By Lemma 2.6, each $f_{\mathrm{i}}$ is continuous almost everywhere on $\square$ and $\square$. Thus there is a constant $\mathrm{u}_{0}$ such that each $\mathrm{f}_{\mathrm{i}}$ is continuous at $\mathrm{S}_{0}=\left(\mathrm{u}_{0}, \mathrm{u}_{0}\right)$ and $\mathrm{R}_{0}=\left((\sqrt{ } 2-1) \mathrm{u}_{0}, \mathrm{u}_{0}\right)$. Choose two sequences $\left\{\mathrm{R}_{\mathrm{j}}\right\} \varnothing \mathrm{R}_{0}$ and $\left\{\mathrm{S}_{\mathrm{k}}\right\} \varnothing \mathrm{S}_{0}$ in the line segments $\mathrm{L}_{0}$ and $\mathrm{B}_{0}$, respectively (see Figure 2.4), of the containment curve of $\mathrm{S}_{0}$. Since each $f_{\mathrm{i}}$ is continuous at $\mathrm{S}_{0}$ and $\mathrm{R}_{0}$, then $\left\{\mathrm{f}_{\mathrm{i}}\left(\mathrm{R}_{\mathrm{j}}\right)\right\}_{\mathrm{j} \square} \square \mathrm{f}_{\mathrm{i}}\left(\mathrm{R}_{0}\right)$ and $\left\{\mathrm{f}_{\mathrm{i}}\left(\mathrm{S}_{\mathrm{k}}\right)\right\}_{\mathrm{k} \square} \square \mathrm{f}_{\mathrm{i}}\left(\mathrm{S}_{0}\right)$, for $\mathrm{i}=1, \ldots, \mathrm{d}$. Suppose w.1.o.g. that $f_{\mathrm{i}}\left(\mathrm{R}_{0}\right)=f_{\mathrm{i}}\left(\mathrm{S}_{0}\right)$ for $\mathrm{i}=1, \ldots, \mathrm{m}$, and that $\mathrm{f}_{\mathrm{i}}\left(\mathrm{R}_{0}\right)<\mathrm{f}_{\mathrm{i}}\left(\mathrm{S}_{0}\right)$ for $\mathrm{i}=\mathrm{m}+1, \ldots, \mathrm{d}$. Since $\mathrm{R}_{0}$ fits in $\mathrm{S}_{0}$, then $f_{\mathrm{i}}\left(\mathrm{R}_{0}\right)=f_{\mathrm{i}}\left(\mathrm{S}_{\mathrm{k}}\right)$ $=f_{\mathrm{i}}\left(\mathrm{S}_{0}\right)$ for $\mathrm{i}=1, \ldots, \mathrm{m}$ and any positive integer $\mathrm{k}$. Furthermore, since $\mathrm{R}_{\mathrm{j}}$ fits in $\mathrm{S}_{0}$, then $f_{\mathrm{i}}\left(\mathrm{R}_{\mathrm{j}}\right)$ $<f_{\mathrm{i}}\left(\mathrm{S}_{0}\right)=f_{\mathrm{i}}\left(\mathrm{S}_{\mathrm{k}}\right)$ for $\mathrm{i}=1, \ldots, \mathrm{m}$ and any positive integers $\mathrm{j}$ and $\mathrm{k}$. Let $\square=\min _{\mathrm{i}=1, \mathrm{~m}}\left\{\mid f_{\mathrm{i}}\left(\mathrm{R}_{0}\right)-\right.$ 
$\left.f_{\mathrm{i}}\left(\mathrm{S}_{0}\right) \mid\right\}$ /2. Since each function $f_{\mathrm{i}}$ is continuous in $\mathrm{R}_{0}$ and $\mathrm{S}_{0}$, there exists an integer $\mathbf{n}_{\mathrm{i}}$ such that if $\mathrm{j}, \mathrm{k}>\mathbf{n}_{\mathrm{i}}$ then $\left|f_{\mathrm{i}}\left(\mathrm{R}_{\mathrm{j}}\right)-f_{\mathrm{i}}\left(\mathrm{R}_{0}\right)\right|<\square$ and $\left|f_{\mathrm{i}}\left(\mathrm{S}_{\mathrm{k}}\right)-f_{\mathrm{i}}\left(\mathrm{S}_{0}\right)\right|<\square$ for $\mathrm{i}=1, \ldots, \mathrm{m}$. Let $\mathbf{n}=$ $\operatorname{Max}_{\mathrm{i}=1, \mathrm{~m}}\left\{\mathbf{n}_{\mathrm{i}}\right\}$. Therefore, if $l>\mathbf{n}$ it follows immediately that $\boldsymbol{f}\left(\mathrm{R}_{l}\right) \leq \boldsymbol{f}\left(\mathrm{S}_{l}\right)$ which contradicts Lemma 2.4.

\subsection{A Reduction of the Containment Problem to Vector Dominance with a Countable Number of Parameters}

We now display a continuous function $\boldsymbol{f}$ with a countable number of coordinates which solves the rectangular containment problem.

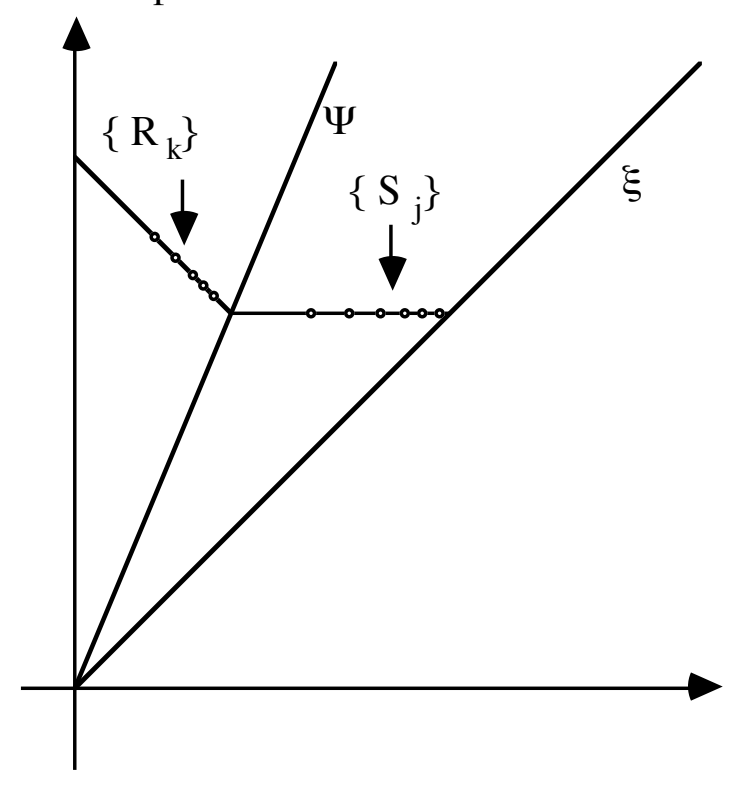

Figure 2.4

Let $\mathbf{U}=\{(\mathrm{w}, 1): 0 \leq \mathrm{w} \leq 1<; \mathrm{w}, 1$ rationals $\}$; $\mathbf{U}$ represents all rectangles with rational width and length. Since $\mathbf{U}$ is countable, the elements of $\mathbf{U}$ can be put in a one-to-one correspondence with the positive integers, yielding a sequence $\left\{\left(\mathrm{w}_{\mathrm{j}}, \mathrm{l}_{\mathrm{j}}\right): 1 \leq \mathrm{j}<\right\}$. Given a rectangle $\mathrm{R}$ with width $w$ and length 1 , let $\square_{j}(\mathrm{R})=\operatorname{Max}\left\{\square:\left(\square w_{j}, \square_{j}\right)\right.$ fits in $\left.R\right\}$ and let $f_{j}(R)=2^{-j} \tan ^{-1}(\square(R))$ for $1 \leq \mathrm{j}<$. Let $\boldsymbol{f}(\mathrm{R})=\left(f_{1}(\mathrm{R}), f_{2}(\mathrm{R}), \ldots\right)$ where $\boldsymbol{f}(\mathrm{R})$ has coordinates $f_{\mathrm{j}}(\mathrm{R})$ for $1 \leq \mathrm{j}<$. It is not difficult (and it is left as an exercise to the reader) to show that the function $\boldsymbol{f}$ so defined is such that rectangle $R_{i}$ fits in rectangle $R_{j}$ if and only if $\boldsymbol{f}\left(R_{i}\right) \leq \boldsymbol{f}\left(R_{j}\right)$; that is,

Theorem 2.2 [34]: Geometric containment of rectangles can be reduced to vector dominance with a countable number of parameters. 


\subsection{Generalizations of the Rectangle Theorem}

The result presented in Theorem 2.1 can be extended to many families of geometrical objects. The next results are proved in [35].

Theorem 2.3: Geometric containment can not be reduced to vector dominance in $\mathbb{R}^{\mathrm{n}}$ regardless of the value of $\mathrm{n}$ for the following families:
a) Rectangles
b) Isoceles triangles (and hence for triangles)
c) Right circular cylinders
d) Polygons with $\mathrm{n}$ sides

These results are a consequence of the following result which is obtained from the proof of Theorem 2.1.

Fix a positive integer $\mathrm{k}$ and a cone $\mathrm{K}$ in $\mathbb{R}^{\mathrm{k}}+=\left\{\mathbf{x}=\left(\mathrm{x}_{1}, \ldots, \mathrm{x}_{\mathrm{k}}\right) \square \mathbb{R}^{\mathrm{k}}\right.$ : $\left.\mathrm{x}_{\mathrm{i}}>0 \mathrm{i}=1, \ldots, \mathrm{k}\right\}$. (That $K$ is a cone means that $K \neq \emptyset$ and $\mathbf{t} \square \square \mathrm{K}$ whenever $\mathbf{x} \square \mathrm{K}$ and $\mathrm{t}>0$ ). We consider a partial order $\square$ on $\mathrm{K}$ which satisfies the following monotonicity and homogeneity hypotheses:

(M) $\quad \mathbf{x} \square \mathrm{K}, \mathbf{y} \square \mathrm{K}, \mathbf{x} \square \mathbf{y}$ together imply $\mathbf{x} \square \mathbf{y}$.

(H) $\quad \mathbf{x} \square \mathrm{K}, \mathbf{y} \square \mathrm{K}, \mathbf{x} \square \mathbf{y}, \mathrm{t}>0$ together imply tx $\square$ ty.

Theorem 2.4 [35]: Suppose that $K$ is a cone in $\mathbb{R}^{k}$ and $\square$ is a partial order on $K$ that satisfies $(M)$ and $(H)$. Suppose that there are distinct points $\mathbf{z}, \mathbf{w}$ in $K$ and sequences $\left(\mathbf{x}^{(\mathrm{n})}\right),\left(\mathbf{y}^{(\mathrm{n})}\right)$ in $\mathrm{K}$ such that:

(1.1) $\mathbf{x}^{(\mathrm{n})} \square \mathbf{w}$ and $\mathbf{z} \square \mathbf{y}^{(\mathrm{n})} \square \mathbf{w}$ for all $\mathrm{n}$.

(1.2) $\mathbf{x}^{(\mathrm{n})} \square \mathbf{y}^{(\mathrm{n})}$ is false for all $\mathrm{n}$.

(1.3) $\mathbf{x}^{(\mathrm{n})} \square \mathbf{z}$ and $\mathbf{y}^{(\mathrm{n})} \square \mathbf{w}$ in $\mathbb{R}^{\mathrm{k}}$ as $\mathrm{n} \square$.

Then $\square$ is not reducible to vector dominance in $\mathbb{R}^{\mathrm{m}}$ for any finite $\mathrm{m}$.

Not all interesting consequences of Theorem 2.4 involve geometric containment. A natural partial order $\square$ is given on the set of all polynomials with real coefficients by declaring that $\mathrm{P}_{1} \square$ $\mathrm{P}_{2}$ provided $\mathrm{P}_{1}(\mathrm{x}) \leq \mathrm{P}_{2}(\mathrm{x})$ for all non-negative real numbers $\mathrm{x}$. It is easy to see that the restriction of $\square$ to the class of linear polynomials is reducible to vector dominance in $\mathbb{R}^{2}$ : associating to $P(x)=a x+b$ the point $j(P)=(a, b)$ does the job. It is perhaps surprising that this 
result does not extend one step further to the class $\mathrm{Q}$ of quadratic polynomials $\mathrm{P}(\mathrm{x})=\mathrm{ax}^{2}+2 \mathrm{bx}$ $+\mathrm{c}$ with real coefficients a,b,c.

Theorem 2.5 [35]: The restriction of the partial order $\square$ to the set $Q$ of quadratic polynomials with real coefficients is not reducible to vector dominance in $\mathbb{R}^{\mathrm{m}}$ for any finite $\mathrm{m}$.

\subsection{Containment for Compact Sets}

In section 4 of [35] it was shown that the family $\square$ of congruence classes of plane rectangles can be mapped into the space $l_{2}$ of square-summable sequences of real numbers in a manner that converts containment to vector dominance, and that this can be accomplished continuously, if $l_{2}$ is equipped with the usual metric $d_{l 2}(u, v)=\left[\square_{n=1}, \quad\left(u_{n}-v_{n}\right)^{2}\right]^{1 / 2}$ for $\mathbf{u}=\left(u_{n}\right)_{n=1}$, and $\mathbf{v}=\left(\mathrm{v}_{\mathrm{n}}\right)_{\mathrm{n}=1}$, in $l_{2}$. We shall now indicate how to extend this result substantially.

Fix a positive integer $\mathrm{k}$ and endow $\mathbb{R}^{\mathrm{k}}$ with its usual Euclidean metric $\mathrm{d}_{\mathrm{k}}$. Let $\square$ denote the family of non-empty compact subsets of $\mathbb{R}^{k}, \sim$ congruence for subsets of $\mathbb{R}^{k}, \underline{F}$ the congruence class of $\mathrm{F} \square \square, \square=\{\underline{\mathrm{F}}: \mathrm{F} \square \square\}, \mathrm{tF}=\{\mathrm{t} \mathbf{x}: \mathbf{x} \square \mathrm{F}\}$ and $\underline{\mathrm{F}}=(\mathrm{tF})^{\sim}$ for $\mathrm{F} \square \square$ and $\mathrm{t}>0$. For $\mathrm{F}_{\mathrm{i}} \square(\mathrm{i}=1,2)$ set

$$
\begin{aligned}
& \left.\square_{1}\left(\mathrm{~F}_{1}, \mathrm{~F}_{2}\right)=\sup _{\mathbf{x} \square \mathrm{F} 1} \quad \inf _{\mathbf{y} \square \mathrm{F} 2} \mathrm{~d}_{\mathrm{k}}(\mathbf{x}, \mathbf{y})\right], \\
& \square_{1}\left(\underline{\mathrm{F}}_{1}, \underline{\mathrm{F}}_{2}\right)=\inf \left\{\square_{1}\left(\mathrm{~F}_{1}, \mathrm{~F}_{2^{\prime}}\right): \mathrm{F}_{2^{\prime}} \sim \mathrm{F}_{2}\right\}, \\
& \square\left(\mathrm{F}_{1}, \mathrm{~F}_{2}\right)=\square_{1}\left(\mathrm{~F}_{1}, \mathrm{~F}_{2}\right)+\square_{1}\left(\mathrm{~F}_{2}, \mathrm{~F}_{1}\right), \\
& \square\left(\underline{F}_{1}, \underline{\mathrm{F}}_{2}\right)=\inf \left\{\square\left(\mathrm{F}_{1}, \mathrm{~F}_{2^{\prime}}\right): \mathrm{F}_{2^{\prime}} \sim \mathrm{F}_{2}\right\} .
\end{aligned}
$$

Thus $(\square, \square)$ and $(\square, \square)$ are metric spaces, and $\square_{1}$ (respectively $\square$ ) is a good measure of closeness of (congruence classes of) compact sets. Clearly $\square_{1} \leq \square$ and $\square_{1} \leq \square$.

Let $\left(\mathrm{L}_{\mathrm{n}}\right)_{\mathrm{n}=1}$, be an enumeration of all non-empty finite unions of boxes $\left[\mathrm{a}_{1}, \mathrm{~b}_{1}\right] \ldots\left[\mathrm{a}_{\mathrm{k}}, \mathrm{b}_{\mathrm{k}}\right]$ with $a_{i}, b_{i}$ rational and $a_{i}<b_{i}$. Define $g_{n}: \square \square \mathbb{R}$ by $g_{n}(\underline{F})=\square_{1}\left(\underline{F}, \underline{L}_{n}\right)$ and let $f_{n}=2^{-n / 2} \tan ^{-1} g_{n}$.

Theorem 2.6 [35]: Let $\mathbf{f}=\left(\mathrm{f}_{\mathrm{n}}\right): \square \square l_{2}$. Then $\mathbf{f}$ is continuous and converts $\mathrm{K}$ on $\square$ into vector dominance in $l_{2}$.

\section{REPRESENTATIONS OF PARTIAL ORDERS USING SETS ON THE PLANE}

Let $F=\left\{S_{1}, \ldots, S_{n}\right\}$ be a family of sets. A partial order $P(X,<)$ on a set $X=\left\{x_{1}, \ldots, X_{n}\right\}$ represents $F=\left\{S_{1}, \ldots, S_{n}\right\}$ if $S_{i}$ is contained in $S_{j}$ implies $x_{i}<x_{j}$ in $P(X,<)$. Conversely $F=\left\{S_{1}, \ldots, S_{n}\right\}$ will be 
called a set representation of $\mathrm{P}(\mathrm{X},<)$. Every partial order has a set representation. For instance, let $\mathrm{S}_{\mathrm{i}}=\left\{\mathrm{x}_{\mathrm{j}} \square \mathrm{X}: \mathrm{x}_{\mathrm{j}}<\mathrm{x}_{\mathrm{i}}\right\} \square\left\{\mathrm{x}_{\mathrm{i}}\right\}$. It is easy to see that $\left\{\mathrm{S}_{1}, \ldots, \mathrm{S}_{\mathrm{n}}\right\}$ is a set representation of $\mathrm{P}(\mathrm{X},<)$. The problem of set representations of partial orders becomes interesting when some restrictions are imposed on the elements of F. For instance, what partial orders have a set representation using circles on the plane?

Representation problems of posets as containment relations have been studied for some time. For example, when the elements of $\mathrm{F}$ are intervals on the real line, $\mathrm{P}(\mathrm{X},<)$ is a partial order of dimension 2 (see Fishburn [11]). When the elements of $F$ are boxes in the n-dimensional space $\mathbb{R}^{n}$ (i.e. sets of points $\left\{\mathbf{x}=\left(\mathrm{x}_{1}, \ldots, \mathrm{x}_{\mathrm{n}}\right): \mathrm{a}_{\mathrm{i}} \leq \mathrm{x}_{\mathrm{i}} \leq \mathrm{b}_{\mathrm{i}} ; \mathrm{a}_{\mathrm{i}}, \mathrm{b}_{\mathrm{i}}\right.$ constants, $\left.\left.\mathrm{i}=1, \ldots, \mathrm{n}\right\}\right)$ the posets thus obtained are exactly all 2 n-dimensional posets (see Golumbic [14]).

In the following sections of this paper we shall be interested in representation problems of partial orders using sets of circles, convex polygons and angular regions on the plane. Representations of partial orders using convex sets on the plane are not hard to obtain. The following theorem gives us our first result on representations:

Theorem 3.1: Every poset has a representation using convex polygons on the plane.

Proof: Let $P(X,<)$ be a poset on a set $X=\left\{x_{1}, \ldots, x_{n}\right\}$. Let $S$ be a convex polygon with $n$ vertices. Label the vertices of $\mathrm{S}$ using the elements $\mathrm{x}_{1}, \ldots, \mathrm{x}_{\mathrm{n}}$ of $\mathrm{X}$ in the clockwise direction along the boundary of $S$. For every $i$ let $S_{i}=\operatorname{Conv}\left(\left\{x_{j} \square X: x_{j}<x_{i}\right\} \square\left\{x_{i}\right\}\right)$, i.e. the convex closure of $\mathrm{S}_{\mathrm{i}}=\left\{\mathrm{x}_{\mathrm{j}} \square \mathrm{X}: \mathrm{x}_{\mathrm{j}}<\mathrm{x}_{\mathrm{i}}\right\} \square\left\{\mathrm{x}_{\mathrm{i}}\right\}$. It follows easily that $\left\{\mathrm{S}_{1}, \ldots, \mathrm{S}_{\mathrm{n}}\right\}$ is a set representation of $\mathrm{P}(\mathrm{X},<)$.

Before continuing our study on representations of partial orders, we will need to study some of their properties.

\subsection{Some Terminology and Definitions}

A binary relation $<$ over a set $\mathrm{X}$ defines a partial order $\mathrm{P}(\mathrm{X},<)$ on $\mathrm{X}$ if it satisfies

(i) $\mathrm{x}<\mathrm{y}, \mathrm{y}<\mathrm{z}$ implies $\mathrm{x}<\mathrm{z}$ (transitivity), and

(ii) $\mathrm{x}<\mathrm{x}$ (antisymmetry).

The partially ordered set $\mathrm{P}(\mathrm{X},<)$ is a linear order if it also satisfies 
(iii) $\mathrm{x}<\mathrm{y}$ or $\mathrm{y}<\mathrm{x}$ for all $\mathrm{x}, \mathrm{y} \square \mathrm{X}$.

Let $\mathrm{P}(\mathrm{X},<)$ be a poset. A realizer of $\mathrm{P}$ of size $\mathrm{k}+1$ is a collection of linear orders $\left\{\mathrm{L}_{\mathrm{o}}\left(\mathrm{X},<_{0}\right)\right.$, $\left.\mathrm{L}_{1}\left(\mathrm{X},<_{1}\right), \ldots, \mathrm{L}_{\mathrm{k}}\left(\mathrm{X},<_{\mathrm{k}}\right)\right\}$ such that $\mathrm{L}_{\mathrm{o}}\left(\mathrm{X},<_{0}\right) \square \mathrm{L}_{1}\left(\mathrm{X},<_{1}\right) \square \ldots \square \mathrm{L}_{\mathrm{k}}\left(\mathrm{X},<_{\mathrm{k}}\right)=\mathrm{P}(\mathrm{X},<)$, where the intersection is defined by $\mathrm{x}<\mathrm{y}$ iff $\mathrm{x}<\mathrm{i} \mathrm{y}$ for all $\mathrm{i}$.

It can be easily proved that every poset can be obtained as the intersection of a number of linear orders. Dushnik and Miller [9] define the dimension of P, denoted dim P, to be the size of the smallest possible realizer of $\mathrm{P}$. Such a realizer is called a minimum realizer of $\mathrm{P}$.

\subsection{Function Diagrams and the Crossing Number of a Partial Order}

Before we start our study of containment problems for families of simple geometric objects (i.e. circles, convex polygons, etc.), we need to study the crossing number of a partial order.

Let $\square=\left\{\mathrm{f}_{1}, \ldots, \mathrm{f}_{\mathrm{m}}\right\}$ be a family of continuous functions $\mathrm{f}_{\mathrm{i}}:[0,1] \square \mathbb{R}, \mathrm{i}=1 \ldots \mathrm{m}$. The family $\square=\left\{\mathrm{f}_{1}, \ldots, \mathrm{f}_{\mathrm{m}}\right\}$ is called normal if the following conditions are satisfied:

a) For any pair of elements $\mathrm{f}_{\mathrm{i}}, \mathrm{f}_{\mathrm{j}} \square \square, \mathrm{i} \neq \mathrm{j}$, the set of values $\mathrm{S}(\mathrm{i}, \mathrm{j})=\left\{\mathrm{x} \square[0,1]: \mathrm{f}_{\mathrm{i}}(\mathrm{x})=\mathrm{f}_{\mathrm{j}}(\mathrm{x})\right\}$ is finite.

b) $\mathrm{f}_{\mathrm{i}}(0) \neq \mathrm{f}_{\mathrm{j}}(0), \mathrm{f}_{\mathrm{i}}(1) \neq \mathrm{f}_{\mathrm{j}}(1) ; \mathrm{i} \neq \mathrm{j}$.

c) Each time the graphs of two functions intersect, they cross each other; that is if $\mathrm{f}_{\mathrm{i}}\left(\mathrm{x}_{0}\right)=\mathrm{f}_{\mathrm{j}}\left(\mathrm{x}_{0}\right)$ there exists an $\square>0$ such that $\mathrm{x}_{0}-\square<\mathrm{x}<\mathrm{x}_{0}<\mathrm{y}<\mathrm{x}_{0}+\square$ implies that $\mathrm{f}_{\mathrm{i}}(\mathrm{x})<\mathrm{f}_{\mathrm{j}}(\mathrm{x})$ and $\mathrm{f}_{\mathrm{i}}(\mathrm{y})>\mathrm{f}_{\mathrm{j}}(\mathrm{y})$ or $\mathrm{f}_{\mathrm{i}}(\mathrm{x})>\mathrm{f}_{\mathrm{j}}(\mathrm{x})$ and $\mathrm{f}_{\mathrm{i}}(\mathrm{y})<\mathrm{f}_{\mathrm{j}}(\mathrm{y})$.

Informally speaking, a set of functions $\square=\left\{\mathrm{f}_{1}, \ldots, \mathrm{f}_{\mathrm{m}}\right\}$ is normal if the graphs of any two elements $f_{i}, f_{j} \square \square$ intersect a finite number of times and each time they intersect, they cross each other.

Let $X=\left\{x_{1}, \ldots, x_{m}\right\}$ be a set, and $P(X, \square)$ a partial order on $X . P(X,<)$ is called a function order (f-order for short) if there exists a normal set of functions $\square=\left\{\mathrm{f}_{1}, \ldots, \mathrm{f}_{\mathrm{m}}\right\}$ such that $\mathrm{x}_{\mathrm{i}}<\mathrm{x}_{\mathrm{j}}$ if $\mathrm{f}_{\mathrm{i}}(\mathrm{x})<\mathrm{f}_{\mathrm{j}}(\mathrm{x})$ for all $\mathrm{x} \square[0,1]$. The set of functions $\square=\left\{\mathrm{f}_{1}, \ldots, \mathrm{f}_{\mathrm{m}}\right\}$ will be called an $\mathrm{f}$-diagram for $\mathrm{P}(\mathrm{X},<)$. We will also say that $\mathrm{P}(\mathrm{X},<)$ represents $\square$. It is easy to prove that every poset is an $\mathrm{f}$ order.

\subsubsection{The Crossing Number of a Partial Order}


The objective in this section is to study a parameter of partial orders called the crossing number of a partial order. The intuitive idea behind the use of the crossing number in the study of geometric problems arises from properties such as:

a) Any two different circles intersect in at most two points.

b) The boundaries of any two different convex n-polygons (not sharing a common line segment in their boundaries) intersect in at most $2 \mathrm{n}$ points.

These properties will then be used to obtain f-diagrams $\square$ for circle orders and n-gon orders in which any two functions of $\square$ intersect at most 2 and $2 n$ times respectively.

Given an $\mathrm{f}$-diagram $\square=\left\{\mathrm{f}_{1}, \ldots, \mathrm{f}_{\mathrm{m}}\right\}$, the crossing number $\square(\square)$ is defined as the maximum over the set $\left\{|\mathrm{S}(\mathrm{i}, \mathrm{j})|: \mathrm{f}_{\mathrm{i}}, \mathrm{f}_{\mathrm{j}} \square \square, \mathrm{i} \neq \mathrm{j}\right\}$; that is, the maximum number of times two elements of $\square$ intersect. The crossing number $\square(\mathrm{P}(\mathrm{X},<)$ ) of a poset $\mathrm{P}(\mathrm{X},<)$ is now defined as $\min \{\square(\square)$ : $\square$ is an $\mathrm{f}$ diagram for $\mathrm{P}(\mathrm{X},<)\} \quad[15]$. Notice that if $\square(\mathrm{P}(\mathrm{X},<))=0$, then $\mathrm{P}(\mathrm{X},<)$ has an $\mathrm{f}$-diagram $\square$ in which no pair of functions of $\square$ intersect, thus $\mathrm{P}(\mathrm{X},<)$ is a linear order. It is also easy to prove that if $\square(\mathrm{P}(\mathrm{X},<))=1$, then the $\operatorname{dim} \mathrm{P}(\mathrm{X},<)$ is 2 .

Let us consider a special type of f-diagram in which the curves are piecewise linear. Let $\mathbf{L}_{0}$, $\mathbf{L}_{1}, \ldots, \mathbf{L}_{\mathrm{k}}$ be vertical lines each labeled from bottom to top by a permutation of the numbers 1 , $2, \ldots, \mathrm{m}$. For each $\mathrm{i}(1 \leq \mathrm{i} \leq \mathrm{m})$ the curve $\mathrm{i}$ consists of the union of the $\mathrm{k}$ line segments which join $\mathrm{i}$ on $\mathbf{L}_{\mathrm{i}-1}$ with $\mathrm{i}$ on $\mathbf{L}_{\mathrm{i}}(1 \leq \mathrm{i} \leq \mathrm{k})$. When $\mathrm{k}=1$, such an $\mathrm{f}$-diagram is called a permutation diagram; when $k \geq 2$, it is called the concatenation of $k$ permutation diagrams . (See Figure 3.1). The next result follows easily:

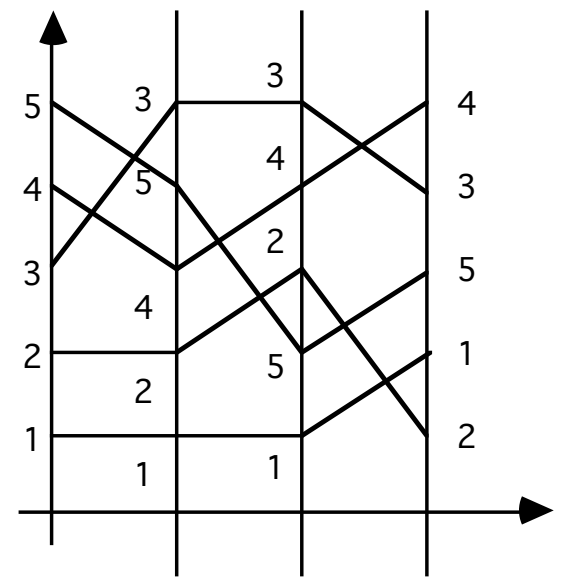

The concatenation of 3 permutation diagrams.

Figure 3.1 
Lemma 3.1 [15]: The crossing number $\square(\mathrm{P}(\mathrm{X},<))$ of a poset of dimension $\mathrm{k}+1$ is at most $\mathrm{k}$.

Proof: Let $\mathrm{P}(\mathrm{X},<)$ be a poset on $\{1, \ldots, \mathrm{m}\}$ and $\left\{\mathrm{L}_{0}\left(\mathrm{X},<_{0}\right), \mathrm{L}_{1}\left(\mathrm{X},<_{1}\right), \ldots, \mathrm{L}_{\mathrm{k}}\left(\mathrm{X},<_{\mathrm{k}}\right)\right\}$ a realizer of $\mathrm{P}(\mathrm{X},<)$ of size $\mathrm{k}+1$. Each $\mathrm{L}_{\mathrm{i}}\left(\mathrm{X},<_{\mathrm{i}}\right)$ defines a permutation $\mathrm{L}_{\mathrm{i}}$ on $\mathrm{X}, \mathrm{i}=0, \ldots, \mathrm{k}$. The result now follows.

We now study some properties of a specific poset. Let $\square_{n}(X,<)$ be the poset with elements $\mathrm{X}=\left\{\mathrm{u}_{1}, \ldots, \mathrm{u}_{\mathrm{n}}, \mathrm{v}_{1}, \ldots, \mathrm{v}_{\mathrm{n}}\right\}$ such that $\mathrm{u}_{\mathrm{i}}<\mathrm{v}_{\mathrm{j}}, \mathrm{i} \neq \mathrm{j}$, and all other pairs of elements in $\square_{\mathrm{n}}(\mathrm{X},<)$ are not comparable. $\square_{n}(X,<)$ is called the Hiraguchi poset. It is well known that the dimension of $\square_{n}(X,<)$ is $n$. It is easy to see that the crossing number of the Hiraguchi poset $\square_{n}(X,<)$ is $2, n \geq 3$ [15]. (See Figure 3.2). The following well known property of $H_{n}$ will be useful.

i ) In any linear extension of $\square_{n}(X,<)$, there exists at most one index i such that $u_{i}>v_{i}$ and for any $\mathrm{k}, \mathrm{l} \neq \mathrm{i}, \mathrm{u}_{\mathrm{k}}<\mathrm{v}_{\mathrm{l}}$.

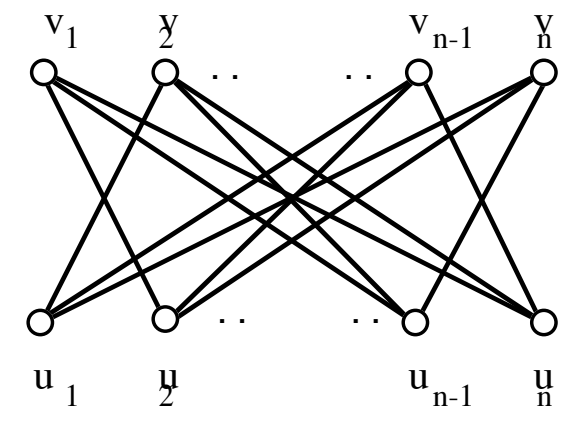

$\mathrm{H}_{\mathrm{n}}$

(a)

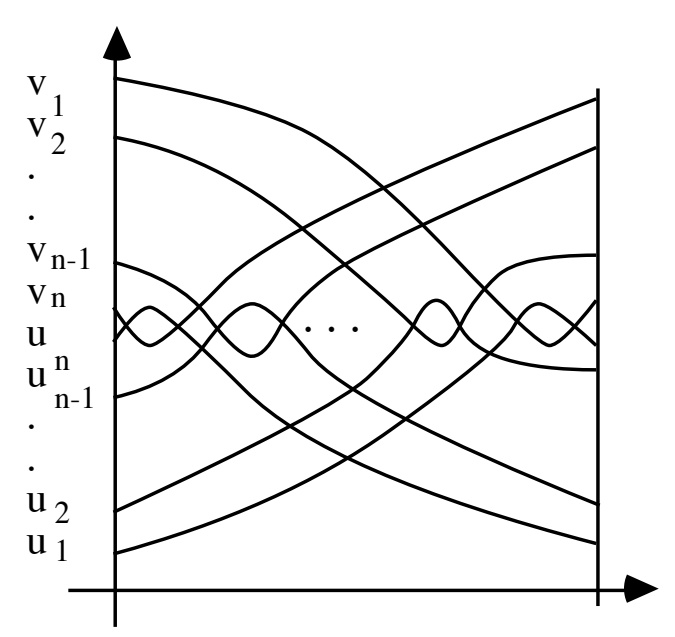

An f-diagram for $\mathrm{H}_{\mathrm{n}}$ with crossing number 2 .

(b)

Figure 3.2

Let $\square$ be an $f$-diagram for $P(X,<), x \square[0,1]$ such that for any $f_{i}, f_{j} \square \square, f_{i}(x) \neq f_{j}(x), i \neq j$. Then $x$ induces a linear extension $\square(\mathrm{x})$ of $\mathrm{P}(\mathrm{X},<)$ in which $\mathrm{x}_{\mathrm{i}}<\mathrm{x}_{\mathrm{j}}$ if $\mathrm{f}_{\mathrm{i}}(\mathrm{x})<\mathrm{f}_{\mathrm{j}}(\mathrm{x})$. When $\mathrm{x}=0,1, \square(0)$ and $\square(1)$ will be called the initial and final linear extensions of $P(X,<)$ with respect to $\square$. The following observation will be used later: 
ii) Let $\square$ be an $f$-diagram represented by a poset $P(X,<)$ and $f_{i}, f_{j} \square \square$ such that $f_{i}, f_{j}$ represent elements which are not comparable in $P(X,<)$, that is the graphs of $f_{i}$ and $f_{j}$ intersect. Then there exists $x \square[0,1]$ such that $f_{i}(x)<f_{j}(x)$; moreover $x$ can be chosen in such a way that $x$ induces a linear extension $\square(\mathrm{x})$ of $\mathrm{P}(\mathrm{X},<)$.

The next result follows trivially.

Lemma 3.2: Let $\square=\left\{\mathrm{f}_{1}, \ldots, \mathrm{f}_{\mathrm{n}}, \mathrm{g}_{1}, \ldots, \mathrm{g}_{\mathrm{n}}\right\}$ be any $\mathrm{f}$-diagram for $\square_{\mathrm{n}}(\mathrm{X},<)$ in which $\mathrm{u}_{\mathrm{i}}$ is represented by $f_{i}$ and $v_{i}$ is represented by $g_{i}$ respectively, $i=1, \ldots, n$. Then there exist $n$ points $\mathrm{x}_{1} \neq \mathrm{x}_{2} \neq \ldots \neq \mathrm{x}_{\mathrm{n}}$ such that $\mathrm{g}_{1}\left(\mathrm{x}_{1}\right)<\mathrm{f}_{1}\left(\mathrm{x}_{1}\right), \mathrm{g}_{2}\left(\mathrm{x}_{2}\right)<\mathrm{f}_{2}\left(\mathrm{x}_{2}\right), \ldots, \mathrm{g}_{\mathrm{n}}\left(\mathrm{x}_{\mathrm{n}}\right)<\mathrm{f}_{\mathrm{n}}\left(\mathrm{x}_{\mathrm{n}}\right)$.

Let $\square_{\mathrm{n}}$ be the poset obtained from $\square_{\mathrm{n}}(\mathrm{X},<)$ as follows: For each subset $\mathrm{S}_{\mathrm{k}}$ of $\{1, \ldots, \mathrm{n}\}$ with

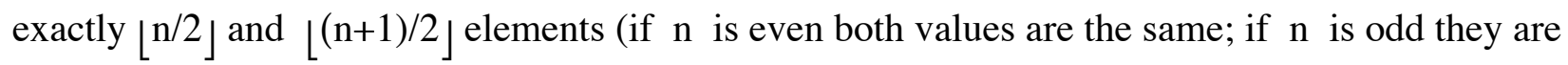
different), insert in $\square_{n}(X,<)$ a new element $s_{k}$ such that $s_{k}>u_{j}, j \square S_{k}, s_{k}<v_{i}, i \square S_{k}$. (See Figure $3.3)$.

Lemma 3.3: The dimension of $\square_{n}$ is $n$.

Proof: To prove this, we notice that $\square_{\mathrm{n}}$ is contained in the poset $2^{\mathrm{n}}$ (under containment) which has dimension $\mathrm{n}$. To see this, let $\mathrm{u}_{\mathrm{i}}$ represent the set $\{\mathrm{i}\}, \mathrm{v}_{\mathrm{i}}$ be the subsets $\{1,2, \ldots, \mathrm{n}\}-\{\mathrm{i}\}$ and $\mathrm{s}_{\mathrm{k}}$ the subset $\mathrm{S}_{\mathrm{k}}$ of $\{1,2, \ldots, \mathrm{n}\}$. The result now follows from the well known result that $\operatorname{dim} 2^{\mathrm{n}}$ is $\mathrm{n}$.

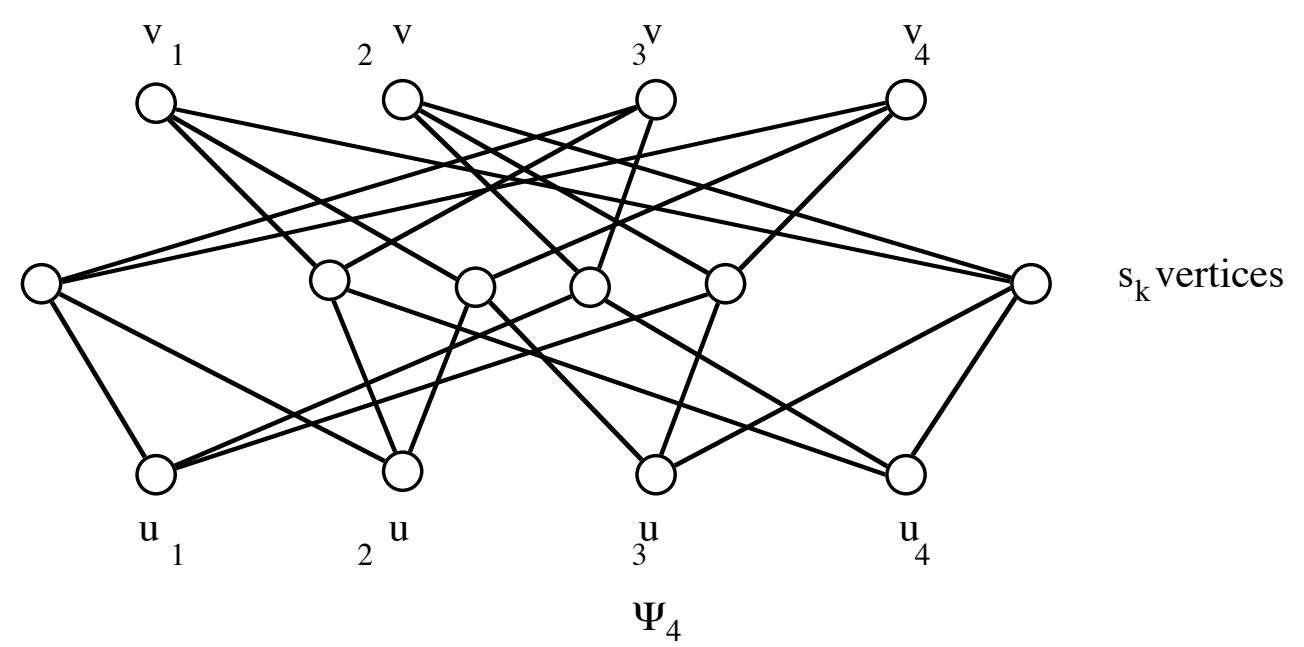

Figure 3.3 
Theorem 3.2 [38]: The crossing number of $\square_{n}$ is $n-1$.

Proof: Let $\square$ ' be an f-diagram represented by $\square_{n}$ in which $u_{i}$ is represented by $f_{i}, v_{i}$ is represented by $g_{i}, i=1, \ldots, n$ and vertices $s_{k}$ are represented by functions $h_{k}$. Clearly $\square$ contains an f-diagram $\square$ for $\square_{\mathrm{n}}(\mathrm{X},<)$ (the one obtained considering the $\mathrm{f}$ and $\mathrm{g}$ functions only). By Lemma 3.2 , there exist $\mathrm{x}_{1} \neq \mathrm{x}_{2} \neq \ldots \neq \mathrm{x}_{\mathrm{n}}$ such that $\mathrm{g}_{1}\left(\mathrm{x}_{1}\right)<\mathrm{f}_{1}\left(\mathrm{x}_{1}\right), \mathrm{g}_{2}\left(\mathrm{x}_{2}\right)<\mathrm{f}_{2}\left(\mathrm{x}_{2}\right), \ldots, \mathrm{g}_{\mathrm{n}}\left(\mathrm{x}_{\mathrm{n}}\right)<\mathrm{f}_{\mathrm{n}}\left(\mathrm{x}_{\mathrm{n}}\right)$. Let us assume without loss of generality that $x_{1}<x_{2}<\ldots<x_{n}$. Let $S_{k}=\{1,3,5, \ldots\}$ and $S_{k}=\{1, \ldots, n\}-$ $\mathrm{S}_{\mathrm{k}}=\{2,4,6, \ldots\}$. We now prove that the graphs of $\mathrm{h}_{\mathrm{k}}$ and $\mathrm{h}_{\mathrm{k}^{\prime}}$ intersect in at least $\mathrm{n}-1$ points. To see this, notice that since $S_{k}=\{1,3,5, \ldots\}, s_{k}<v_{2}, v_{4}, v_{6}, \ldots$. Then $h_{k}(x)<g_{i}(x), i=2,4,6, \ldots$. Moreover since $\mathrm{s}_{\mathrm{k}}>\mathrm{u}_{1}, \mathrm{u}_{3}, \mathrm{u}_{5}, \ldots$ it follows that $\mathrm{h}_{\mathrm{k}}(\mathrm{x})>\mathrm{f}_{\mathrm{i}}(\mathrm{x}), \mathrm{i}=1,3,5, \ldots$. Similarly, we can prove that $h_{k^{\prime}}(x)>f_{i}(x), i=2,4,6, \ldots$ and $h_{k^{\prime}}(x)<g_{i}(x), i=1,3,5, \ldots$. Hence for $\mathrm{i}=1,3,5, \ldots$ we have $h_{k^{\prime}}\left(x_{i}\right)<g_{i}\left(x_{i}\right)<$ $\mathrm{f}_{\mathrm{i}}\left(\mathrm{x}_{\mathrm{i}}\right)<\mathrm{h}_{\mathrm{k}}\left(\mathrm{x}_{\mathrm{i}}\right)$, i.e. $\mathrm{h}_{\mathrm{k}}\left(\mathrm{x}_{\mathrm{i}}\right)<\mathrm{h}_{\mathrm{k}^{\prime}}\left(\mathrm{x}_{\mathrm{i}}\right)$. Similarly $\mathrm{h}_{\mathrm{k}}\left(\mathrm{x}_{\mathrm{i}}\right)<\mathrm{g}_{\mathrm{i}}\left(\mathrm{x}_{\mathrm{i}}\right)<\mathrm{f}_{\mathrm{i}}\left(\mathrm{x}_{\mathrm{i}}\right)<\mathrm{h}_{\mathrm{k}^{\prime}}\left(\mathrm{x}_{\mathrm{i}}\right)$, i.e. $\mathrm{h}_{\mathrm{k}^{\prime}}\left(\mathrm{x}_{\mathrm{i}}\right)<\mathrm{h}_{\mathrm{k}}\left(\mathrm{x}_{\mathrm{i}}\right)$, $\mathrm{i}=2,4,6, \ldots$. However since $x_{1}<x_{2}<\ldots<x_{n}, h_{k}$ intersects $h_{k^{\prime}}$ in each interval $\left(x_{i}, x_{i+1}\right), i=1, \ldots, n-1$, i.e. $h_{k}$ intersects $h_{k^{\prime}}$ at least $n-1$ times. Then $\square\left(\square_{n}\right) \geq n-1$. But since $\operatorname{dim} \square_{n}=n$, by Lemma 3.1, $\square\left(\square_{n}\right) \leq n-1$. Therefore $\square\left(\square_{n}\right)=n-1$.

We are now ready to study circle orders, angle orders and n-gon orders.

\subsection{Circle Orders}

Let $\mathrm{X}=\left\{\mathrm{X}_{1}, \ldots, \mathrm{X}_{\mathrm{m}}\right\}$ be a set, and $\mathrm{P}(\mathrm{X},<)$ a partial order on $\mathrm{X} . \mathrm{P}(\mathrm{X},<)$ is called a circle order if there exists a family $\square=\left\{\mathrm{P}_{1}, \ldots, \mathrm{P}_{\mathrm{m}}\right\}$ of circles on the plane such that $\mathrm{x}_{\mathrm{i}}<\mathrm{x}_{\mathrm{j}}$ iff circle $\mathrm{P}_{\mathrm{i}}$ is contained inside $\mathrm{P}_{\mathrm{j}}$. $\square=\left\{\mathrm{P}_{1}, \ldots, \mathrm{P}_{\mathrm{m}}\right\}$ will be called a circle representation of $\mathrm{P}(\mathrm{X},<)$. It is easy to see that all partial orders of dimension 2 are circle orders. In this section we will prove that there are partial orders of dimension 4 that are not circle orders. At present we do not know if all partial orders of dimension 3 are circle orders or not. We will also prove that the dual of a circle order is a circle order and that the composition of two circle orders is also a circle order.

A circle representation $\square=\left\{\mathrm{P}_{1}, \ldots, \mathrm{P}_{\mathrm{m}}\right\}$ of a circle order $\mathrm{P}(\mathrm{X},<)$ is called a normal representation of $\mathrm{P}(\mathrm{X},<)$ if $\operatorname{int}\left(\mathrm{P}_{1}\right) \square \ldots \square \operatorname{int}\left(\mathrm{P}_{\mathrm{m}}\right) \neq \varnothing$; where int $(\mathrm{S})$ denotes the interior of $\mathrm{S}$.

The next result follows:

Lemma 3.4 [38]: Any circle order $\mathrm{P}(\mathrm{X},<)$ has a normal representation.

Proof: Let $\square=\left\{\mathrm{P}_{1}, \ldots, \mathrm{P}_{\mathrm{m}}\right\}$ be a circle representation of $\mathrm{P}(\mathrm{X},<)$. Let $\square$ be the maximum 
distance among the centres of the circles in $\square$. For any circle $P_{i}$ with radius $r_{i}$ in $\square$, let $P_{i}\left(r_{i}+2 \square\right)$ be the circle concentric with $P_{i}$ with radius $r_{i}+2 \square$. Then $P_{i}$ is contained inside $P_{j}$ if and only if $\mathrm{P}_{\mathrm{i}}\left(\mathrm{r}_{\mathrm{i}}+2 \square\right)$ is contained in $\mathrm{P}_{\mathrm{j}}\left(\mathrm{r}_{\mathrm{j}}+2 \square\right)$. Hence $\square^{\prime}=\left\{\mathrm{P}_{1}\left(\mathrm{r}_{1}+2 \square\right), \ldots, \mathrm{P}_{\mathrm{m}}\left(\mathrm{r}_{\mathrm{m}}+2 \square\right)\right\}$ is also a circle representation for $\mathrm{P}(\mathrm{X},<)$. It is now easy to see that $\square^{\prime}=\left\{\mathrm{P}_{1}\left(\mathrm{r}_{1}+2 \square\right), \ldots, \mathrm{P}_{\mathrm{m}}\left(\mathrm{r}_{\mathrm{m}}+2 \square\right)\right\}$ is a normal representation of $\mathrm{P}(\mathrm{X},<)$.

An important consequence of Lemma 3.4 is the next result:

Theorem 3.3 [38]: The crossing number of a circle order is at most two.

Proof: Let $\square=\left\{\mathrm{P}_{1}, \ldots, \mathrm{P}_{\mathrm{m}}\right\}$ be a normal representation of a circle order $\mathrm{P}(\mathrm{X},<)$. Let $\mathrm{Q}$ be a point in the common intersection of $\mathrm{P}_{1}, \ldots, \mathrm{P}_{\mathrm{m}}$ and $\mathrm{L}_{\mathrm{Q}}$ a ray starting at $\mathrm{Q}$ which does not meet any point in which two circles of $\square=\left\{\mathrm{P}_{1}, \ldots, \mathrm{P}_{\mathrm{m}}\right\}$ intersect. (See Figure 3.4). Then using what in topology is known as surgery, cut the plane along $\mathrm{L}_{\mathrm{Q}}$ and stretch it so that one side of the cut goes to the $\mathrm{Y}$-axis and the other to the line $\mathrm{x}=1$. Then we obtain an $\mathrm{f}$-diagram $\square$ for $\mathrm{P}(\mathrm{X},<)$ in which every circle $P_{i}$ of $\square$ is mapped into a function $f_{i}$. (See Figure 3.4). Moreover, since any two circles intersect in at most two points, any two functions of $\square$ intersect in at most two points. Then $\square(\square)=2$ and $\square(\mathrm{P}(\mathrm{X},<)) \leq 2$.
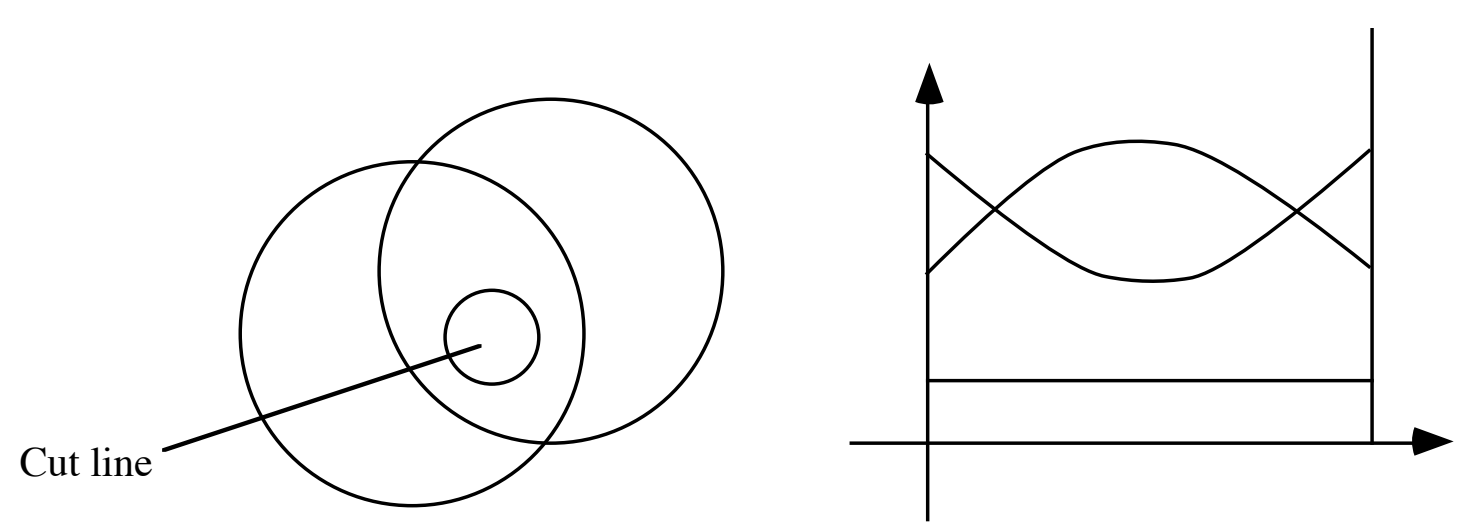

Figure 3.4

Corollary 3.1 [38]: $\square_{4}$ is not a circle order.

We notice here that $\square_{4}$ is critical in the sense that if any element fron $\square_{4}$ is deleted, the partial order thus obtained becomes a circle order. Moreover, $\square_{4}$ is the smallest partial order known to us that is not a circle order. We conjecture that $\square_{4}$ is the smallest poset which is not a circle 
order.

Conjecture 3.1: All finite posets of dimension $\leq 3$ are circle orders.

In a recent paper, Scheinerman and Wierman proved the following result:

Theorem S.W. [36]: $Z^{3}$ is not a circle order.

This proves that the infinite version of Conjecture 3.1 is false. Another open problem in this direction is this:

Problem 3.1: Is it true that all partial orders with crossing number at most 2 are circle orders? If not, find a partial order with crossing number 2 which is not a circle order.

At this point, we should mention that $H_{n}$ is a circle order for all values of $n$. Thus for every $n$ there are partial orders of dimension $n$ which are circle orders. However the crossing number of $\mathrm{H}_{\mathrm{n}}$ is 2. Thus the importance of Problem 3.1.

\subsubsection{Some Properties of Circle Orders}

Using a similar technique to the one used in Lemma 3.4, we can prove the following result:

Theorem 3.4: The dual of $\mathrm{P}^{*}(\mathrm{X},<)$, a circle order $\mathrm{P}(\mathrm{X},<)$, is also a circle order.

Proof: Let $\square=\left\{\mathrm{P}_{1}, \ldots, \mathrm{P}_{\mathrm{m}}\right\}$ be a circle representation of $\mathrm{P}(\mathrm{X},<)$. Let $\square$ be the maximum distance among the centers of the circles in $\square$. For any circle $P_{i}$ with radius $r_{i}$ in $\square$, let $P_{i}\left(\mid r_{i^{-}}\right.$ $2 \square \mid$ ) be the circle concentric with $\mathrm{P}_{\mathrm{i}}$ with radius $\mid \mathrm{r}_{\mathrm{i}}-2 \square$. The reader can easily verify that $\square^{\prime}=\left\{\mathrm{P}_{1}\left(\left|\mathrm{r}_{1}-2 \square\right|\right), \ldots, \mathrm{P}_{\mathrm{m}}\left(\left|\mathrm{r}_{\mathrm{m}}-2 \square\right|\right)\right\}$ is a circle representation for $\mathrm{P}^{*}(\mathrm{X},<)$.

Given two partial orders $\mathrm{Q}\left(\mathrm{X},<^{\prime}\right)$ and $\mathrm{R}\left(\mathrm{Y},<^{\prime \prime}\right)$ we define their composition $\mathrm{P}(\mathrm{X} \quad \mathrm{Y},<)$ as follows: $\left(\mathrm{x}_{1}, \mathrm{y}_{1}\right)<\left(\mathrm{x}_{2}, \mathrm{y}_{2}\right)$ if $\mathrm{x}_{1}<\mathrm{x}_{2}$ and $\mathrm{y}_{1}<" \mathrm{y}_{2}$. Next we prove:

Theorem 3.5: The composition $\mathrm{P}(\mathrm{X} Y,<)$ of two circle orders $\mathrm{Q}\left(\mathrm{X},<^{\prime}\right)$ and $\mathrm{R}\left(\mathrm{Y},<^{\prime \prime}\right)$ is a circle order.

Before we prove Theorem 3.5 we need the following results: 
A representation $\square=\left\{\mathrm{P}_{1}, \ldots, \mathrm{P}_{\mathrm{m}}\right\}$ of a circle order $\mathrm{P}(\mathrm{X},<)$ is called an $(\mathrm{r}, \square)$-circle representation of $\mathrm{P}(\mathrm{X},<)$ if all the elements of $\square$ are contained in the annular region determined be the circles with center in the origin of radius $\mathrm{r}$ and $\mathrm{r}+\square$

Lemma 3.5: Any circle order has an (r, $\square$-circle representation.

Proof: Let $\square=\left\{\mathrm{P}_{1}, \ldots, \mathrm{P}_{\mathrm{m}}\right\}$ be a normal representation of a circle order. Suppose that the origin belongs to $\mathrm{P}_{1} \square \ldots \square \mathrm{P}_{\mathrm{m}}$. Let us consider two circles $\mathrm{C}_{0}$ and $\mathrm{C}_{\square}$ of radius 0 and $\square$ with center in the origin such that $\mathrm{C}_{\square}$ contains all the elements of $\square$. Let $\square(\square$ be the representation obtained from $\square$ by increasing the radii of the elements of $\square$ by $\square$. Then all the elements of $\square$ are contained within the annular region determined by $\mathrm{C}_{0}(\square)$ and $\mathrm{C}_{\square}(\square)$, the circles with center in the origin and radii $\square$ and $\square+\square$ Choosing $\square$ such that $(\square+\square) / \square k(\mathrm{r}+\square)$ and reescaling $\square$ down to $\mathrm{r}$ gives us the desired result.

We are ready to prove Theorem 3.5.

Proof of Theorem 3.5: Let $\square=\left\{\mathrm{P}_{1}, \ldots, \mathrm{P}_{\mathrm{m}}\right\}$ be a normal representation of a circle order $\mathrm{Q}\left(\mathrm{X},<^{\prime}\right)$ on $\mathrm{X}=\{1, \ldots, \mathrm{m}\}$. We can assume that no two elements of $\square$ are tangent. For each $\mathrm{P}_{\mathrm{i}} \square \square$ with radius $r_{i}$ there exists an $\square_{i}$ such that if each $P_{i}$ is substituted by the annular region $A_{i}$ determined by $\mathrm{P}_{i}$ and $\mathrm{P}_{\mathrm{i}}\left(\mathrm{r}_{\mathrm{i}}+\square\right)$ then the containment structure of $\square$ remains unchanged, $\mathrm{i}=1, \ldots, \mathrm{m}$. Let us substitute each $A_{i}$ by an $\left(r_{i}, \square\right)$-representation of $Q(Y,<")$. This will produce a circle representation for the composition of $\mathrm{P}\left(\mathrm{X},<^{\prime}\right)$ and $\mathrm{R}\left(\mathrm{Y},<^{\prime \prime}\right)$.

\subsection{Representations of Partial Orders Using Regular Convex Polygons}

A partial order $\mathrm{P}(\mathrm{X},<)$ on a set $\mathrm{X}=\left\{\mathrm{x}_{1}, \ldots, \mathrm{X}_{\mathrm{m}}\right\}$ is called a polygonal partial order if there exists a family of polygons $\square=\left\{\mathrm{P}_{1}, \ldots, \mathrm{P}_{\mathrm{m}}\right\}$ such that $\mathrm{S}_{\mathrm{i}}$ is contained within $\mathrm{S}_{\mathrm{j}}$ if and only if $\mathrm{x}_{\mathrm{i}}<\mathrm{x}_{\mathrm{j}}$ in $\mathrm{P}(\mathrm{X},<)$. $\square=\left\{\mathrm{P}_{1}, \ldots, \mathrm{P}_{\mathrm{m}}\right\}$ will be called polygonal representation of $\mathrm{P}(\mathrm{X},<)$. From now on, we shall assume that a point cannot be a vertex of more than one polygon of a polygon representation of a partial order and that any two edges of different polygons intersect at most in one point.. In this section we study the problem of representing partial orders using convex polygons on the plane. By Theorem 3.1 every partial order has a polygonal representation. In this section we will study partial orders arising from families of regular polygons with parallel sides ; for instance we will consider families of equilateral triangles with bases parallel to the $\mathrm{x}$-axis. The 
next result was our original motivation to study these families of partial orders.
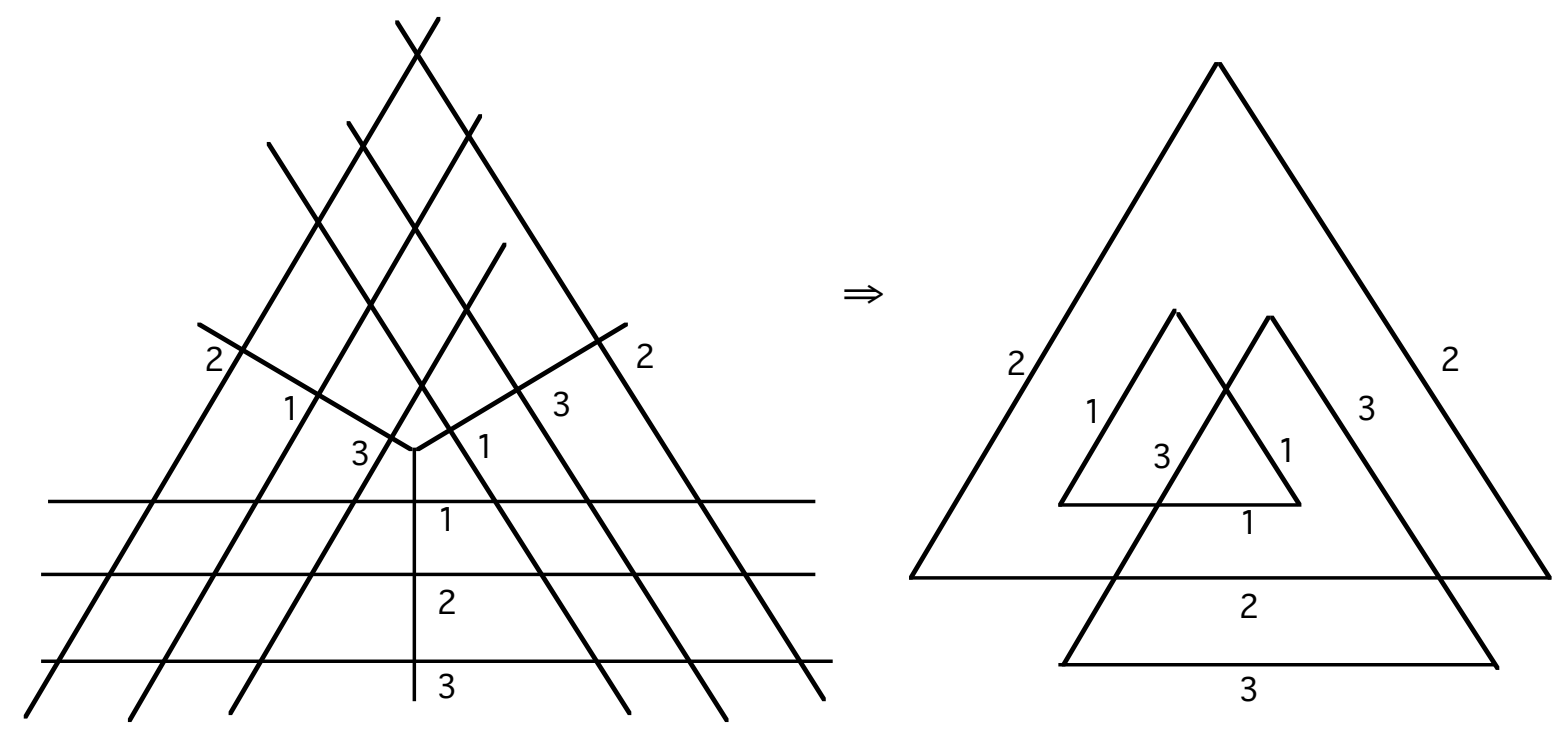

Figure 3.5

Theorem 3.6 [32]: Every poset of dimension 3 can be represented using equilateral triangles.

Proof: Let $P(X,<)$ be a poset of dimension 3 on a set $X=\left\{x_{1}, . ., x_{n}\right\}$ and $L_{1}, L_{2}, L_{3}$ linear extensions of $\mathrm{P}(\mathrm{X},<)$ such that $\mathrm{L}_{1} \square \mathrm{L}_{2} \square \mathrm{L}_{3}=\mathrm{P}(\mathrm{X},<)$. Take 3 rays $\mathrm{R}_{1}, \mathrm{R}_{2}, \mathrm{R}_{3}$ emanating from the origin at $120^{\circ}$ angles. Label $n$ points in $R_{i}$ using the elements of $X$ in the order determined by $L_{i}$, $\mathrm{i}=1,2,3$. For a point $\mathrm{x}_{\mathrm{j}}$ in $\mathrm{R}_{\mathrm{i}}$ let $\mathrm{L}_{\mathrm{i}, \mathrm{j}}$ be the line perpendicular to $\mathrm{R}_{\mathrm{i}}$ through $\mathrm{x}_{\mathrm{j}}, \mathrm{i}=1,2,3, \mathrm{j}=1, \ldots, n$. Each such line determines a semiplane $S_{i, j}$ containing the origin. For each $x_{i} \square X$ let $T_{i}$ be the triangle defined by $S_{1, j} \square S_{2, j} \square S_{3, j}$. It follows that $T_{i}$ is contained within $T_{j}$ if and only if $x_{i}<x_{j}$ in $\mathrm{P}(\mathrm{X},<)$. (See Figure 3.5).

Thus a natural question to ask is what posets can be represented using regular n-gons. For instance: What posets can be represented using equilateral triangles, squares, pentagons...? Can we extend the result in Theorem 3.6 to higher dimensions? Unfortunately the answer to the last question is negative. In fact we will prove that $\square_{4}$ is not representable using regular n-gons regardless of the value of $\mathrm{n}$. We recall that in this section, we shall be concerned only with regular n-gons all having the same orientation. A representation $\square=\left\{S_{1}, \ldots, S_{n}\right\}$ of a partial order $\mathrm{P}(\mathrm{X},<)$ is called normal if $\mathrm{S}_{1} \square \ldots \square \mathrm{S}_{\mathrm{n}} \neq \varnothing$.

A poset will be called a regular n-gon order if it can be represented using regular n-gons all 
with the same orientation. Our first result concerning regular n-gon orders is this:

Lemma 3.6 [32]: Any regular n-gon order has a normal representation.

Proof: Let $\square=\left\{\mathrm{P}_{1}, \ldots, \mathrm{P}_{\mathrm{k}}\right\}$ be a representation of an regular $\mathrm{n}$-gon order $\mathrm{P}(\mathrm{X},<)$ on a set $\mathrm{X}=\left\{\mathrm{x}_{1}, \ldots, \mathrm{x}_{\mathrm{k}}\right\}$ using regular $\mathrm{n}$-gons. Suppose that all elements of $\square$ are contained in a circle of radius 1 . For each element $\mathrm{P}_{\mathrm{i}}$ of $\square$ let $\mathrm{P}_{\mathrm{i}}{ }^{\prime}$ be the regular $n$-gon obtained from $\mathrm{P}_{\mathrm{i}}$ as follows: For each edge $e_{j}$ of $P_{i}$ let $S_{j}$ be the semiplane containing $P_{i}$ defined by the line $L_{j}$ parallel to $e_{j}$ at distance 1 from $e_{j}, j=1, \ldots, n$. Let $P_{i}^{\prime}$ be the regular $n$-gon determined by $S_{1} \square \ldots \square S_{n}$. It follows immediately that $\mathrm{R}^{\prime}=\left\{\mathrm{P}_{1}{ }^{\prime}, \ldots \mathrm{P}_{\mathrm{k}}{ }^{\prime}\right\}$ is a normal representation of $\mathrm{P}(\mathrm{X},<)$. (See Figure 3.6).

We can now prove

Theorem 3.7 [32]: The dimension of every regular n-gon order is at most $n$. Moreover, there are regular $\mathrm{n}$-gon orders with dimension $\mathrm{n}$.

Proof: Let $\square=\left\{\mathrm{P}_{1}, . ., \mathrm{P}_{\mathrm{k}}\right\}$ be a normal representation of a regular n-gon order $\mathrm{P}(\mathrm{X},<)$. Suppose that the origin belongs to the common intersection of $\mathrm{P}_{1}, \ldots, \mathrm{P}_{\mathrm{k}}$. For each edge $\mathrm{e}_{\mathrm{i}}$ of $\mathrm{P}_{1}$ let $R_{i}$ be the ray emanating from the origin that intersects $e_{i}$ perpendicularly. Each $R_{i}$ defines a linear extension $\mathrm{L}_{\mathrm{i}}$ of $\mathrm{P}(\mathrm{X},<)$ (the order in which the elements of $\square$ are intersected by $\mathrm{R}_{\mathrm{i}}$ ), $\mathrm{i}=1, \ldots, \mathrm{n}$. It is easy to see that $\mathrm{L}_{1}, \ldots, \mathrm{L}_{\mathrm{n}}$ is a realizer of $\mathrm{P}(\mathrm{X},<)$. (See Figure 3.6).
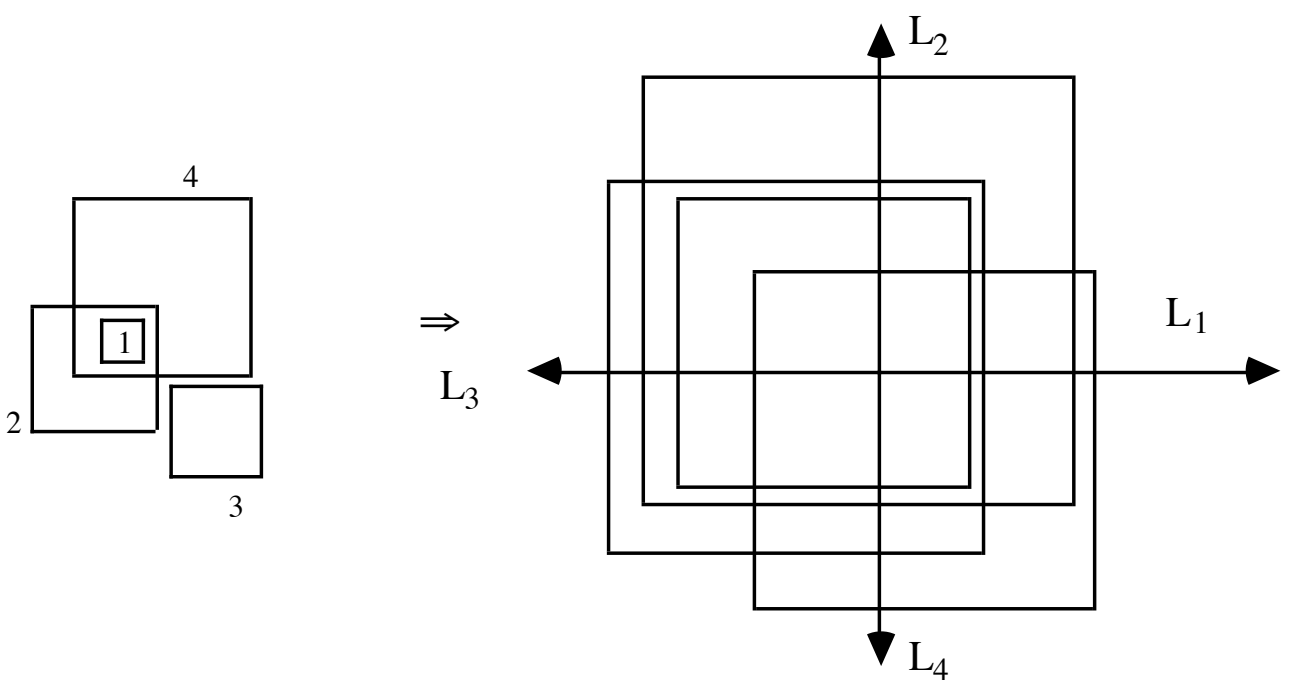

$$
\begin{aligned}
& \left.\mathrm{L}_{1}=\{1,2,4,3)\right\}, \mathrm{L}_{2}=\{3,1,2,4\} \\
& \mathrm{L}_{3}=\{3,1,4,2\}, \mathrm{L}_{4}=\{1,4,2,3\}
\end{aligned}
$$

Figure 3.6 
Next we shall prove that the Hiraguchi poset $\mathrm{H}_{\mathrm{n}}$ is a regular $\mathrm{n}$-gon order set. We will prove this result for the case $n=3$. The proof can easily be adapted for other values of $n$. Take an equilateral triangle $\mathrm{T}$ on the plane. Let us extend each edge $\mathrm{e}_{\mathrm{i}}$ of $\mathrm{T}$ at both ends by a constant $\square$ to obtain $\mathrm{e}_{\mathrm{i}}^{\prime}, \mathrm{i}=1,2,3$. Using $\mathrm{e}_{\mathrm{i}}^{\mathrm{i}}$, let us construct an equilateral triangle $\mathrm{T}_{\mathrm{i}}$ containing $\mathrm{T}$, one of whose edges is $\mathrm{e}_{\mathrm{i}}{ }$. It is easy to see that $\mathrm{T}_{\mathrm{i}}$ is well defined, $\mathrm{i}=1,2,3$. In the perpendicular to the mid-point of $e_{i}$, we can always choose a point $\mathrm{p}_{i}$ not contained in $\mathrm{T}_{\mathrm{i}}, \mathrm{i}=1,2,3$. Then the partial order representing $\left\{\mathrm{T}_{1}, \mathrm{~T}_{2}, \mathrm{~T}_{3}, \mathrm{p}_{1}, \mathrm{p}_{2}, \mathrm{p}_{3}\right\}$ is $\mathrm{H}_{3}$. (See Figure 3.7).

We now proceed to prove that there are partial orders of dimension 4 which are not regular ngon orders regardless of the value of $n$. In order to prove this, we need the next lemma.

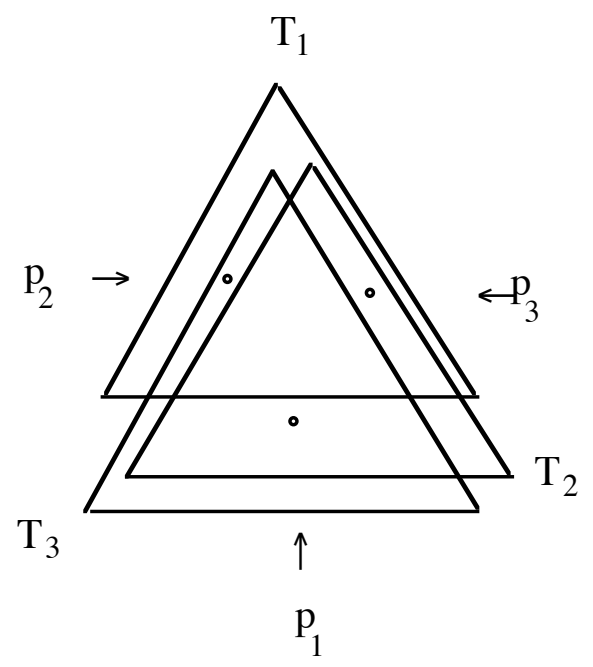

Figure 3.7

Lemma 3.7 [32]: Let $P(X,<)$ be a regular n-gon order $(n \geq 3)$. Then the crossing number of $\mathrm{P}(\mathrm{X},<)$ is at most two.

Proof: Let $\square=\left\{\mathrm{P}_{1}, \ldots, \mathrm{P}_{\mathrm{n}}\right\}$ be a normal representation of $\mathrm{P}(\mathrm{X},<)$ using regular $\mathrm{n}$-gons all with the same orientation. Let $\mathrm{p}$ be a point in $\mathrm{P}_{1} \square \ldots \square \mathrm{P}_{\mathrm{n}}$. Let $\mathrm{L}_{\mathrm{p}}$ be a ray emanating from $\mathrm{p}$ that does not meet any point in which the boundaries of any two elements of $\square$ intersect. Then using surgery (as in Theorem 3.3), we can cut the plane along $\mathrm{L}_{\mathrm{p}}$ and stretch it so that one side of the cut goes to the $y$-axis and the other to the line $x=1$. In doing so, the boundary of each $P_{j}$ is mapped into a continuous function $\mathrm{f}_{\mathrm{i}}[0,1] \square \mathbb{R}$. Then we obtain an $\mathrm{f}$-diagram $\square=\left\{\mathrm{f}_{1}, \ldots, \mathrm{f}_{\mathrm{m}}\right\}$ for $\mathrm{P}(\mathrm{X},<)$ with crossing number at most 2. (See Figure 3.8). 
Theorem 3.8 [32]: There are posets with dimension $n>3$ which are not regular n-gon orders.

Proof: By Theorem 3.2 there are posets of dimension $n$ and crossing number $n-1, n \geq 1$. For $\mathrm{n}>3$ these posets have crossing number $n-1 \geq 3$, and then by Lemma 3.7 can not be represented using regular n-gons.
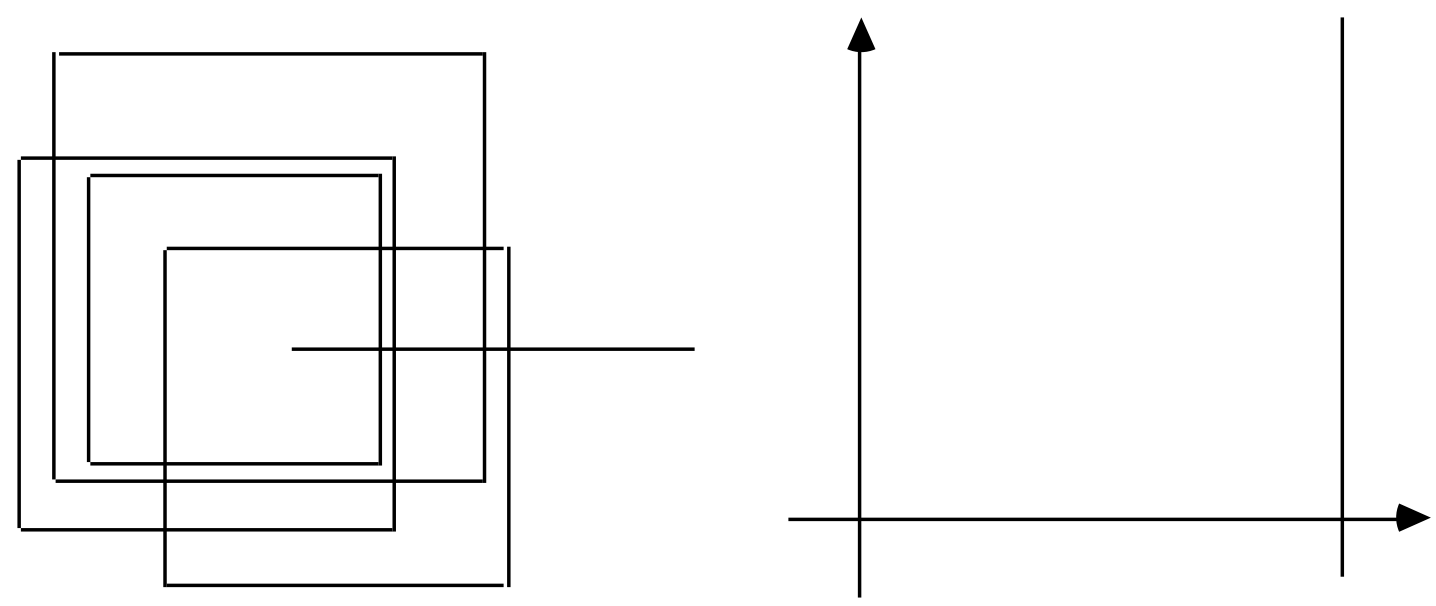

Figure 3.8

Corollary 3.2 [32]: $\square_{4}$ is not a regular n-gon order regardless of the value of $n$.

$\square_{4}$ is the smallest partial order known to us that is not a regular n-gon order. It has only 14 elements. We strongly believe that $\square_{4}$ is the smallest ordered set that is not a regular n-gon order.

As in the case of circle orders, we can prove the following results in a similar way:

Theorem 3.9: The dual of a regular n-gon order is also a regular n-gon order.

Theorem 3.10: The composition of two regular n-gon orders is also a regular n-gon order.

The proofs for these results are very similar to those of Theorems 3.4 and 3.5. The equivalent of Lemma 3.5 can also be easily obtained.

\subsection{Dimension 3}

One of the most interesting areas in the study of geometric containment problems is the study 
of circle orders. In Section 3.4 we proved that the crossing number of circle orders is at most 2. This gives us partial orders of dimension 4 which are not circle orders. On the other hand, it is easy to see that all partial orders with dimension 2 are circle orders. Then from a dimension point of view, the standing problem is that of deciding if all partial orders with dimension 3 are circle orders. This seems to be a very hard problem. In this section, we shall present a result which provides good evidence that the answer to the above problem is positive. We will prove that partial orders with dimension 3 are regular $n$-gon orders, regardless of the value of $n, n \geq 3$. Notice that as $\mathrm{n} \square$ the polygons thus obtained converge to circles. Unfortunately, we cannot apply a limit type argument to our result to solve the circle orders problem.

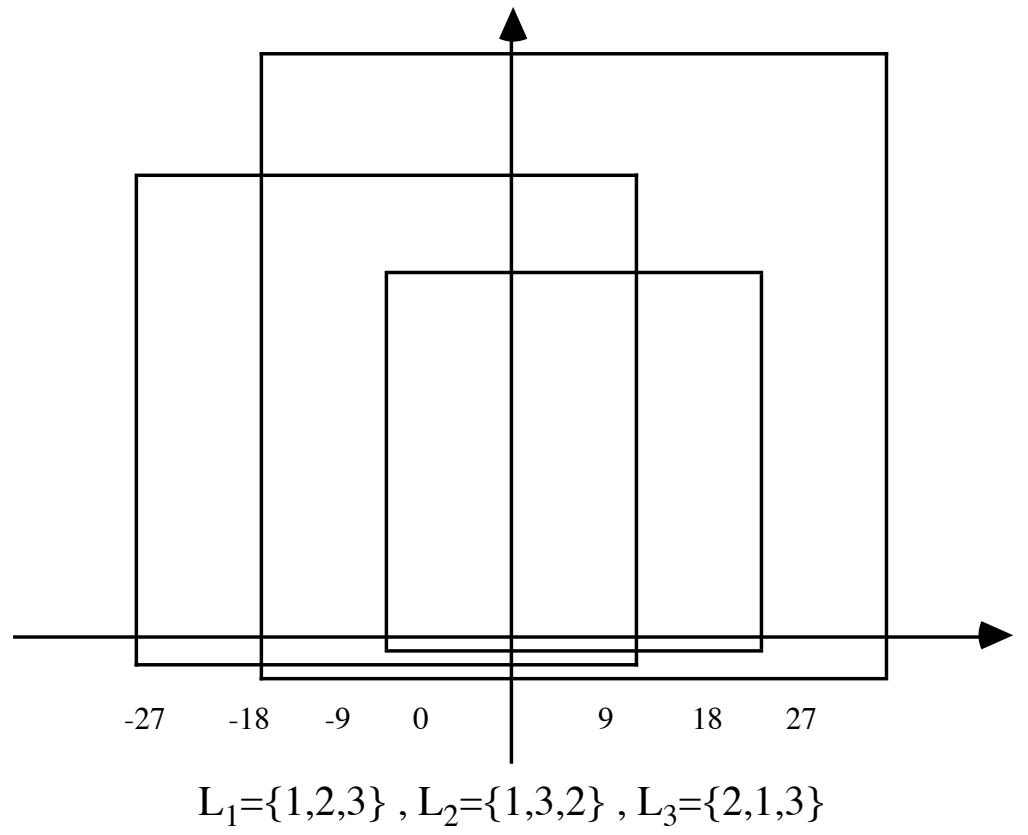

Figure 3.9

Theorem 3.11 [32]: Every partial order with dimension 3 is a regular $n$-gon order, $n \geq 3$.

Proof: As in previous cases, we will prove our result for $n=4$. For larger values of $n$, the proof can be easily adapted to obtain the desired result. Let $\mathrm{P}(\mathrm{X},<)$ be a partial order of dimension 3 on $X=\{1, \ldots, m\}$.

Let $\left\{\mathrm{L}_{1}\left(\mathrm{X},<_{1}\right), \mathrm{L}_{2}\left(\mathrm{X},<_{2}\right), \mathrm{L}_{3}\left(\mathrm{X},<_{3}\right)\right\}$ be a realizer of $\mathrm{P}(\mathrm{X},<)$. Suppose w.l.o.g. that $\mathrm{L}_{1}\left(\mathrm{X},<_{1}\right)$ is the linear extension in which $\mathrm{i}<_{1} \mathrm{j}$ iff as integers $\mathrm{i}<\mathrm{j}$. Each $\mathrm{L}_{\mathrm{i}}\left(\mathrm{X},<_{\mathrm{i}}\right)$ defines a permutation $\pi_{\mathrm{i}}$ on $\{1, \ldots, \mathrm{m}\}, \mathrm{i}=2,3$. Using $\pi_{2}$, label the points with coordinates $\left(\mathrm{km}^{2}, 0\right)$ on the $\mathrm{x}$-axis with the element $\pi_{2}{ }^{-1}(\mathrm{k}), \mathrm{k}=1, \ldots, \mathrm{m}$. Similarly, label the points $\left(-\mathrm{km}^{2}, 0\right)$ on the $\mathrm{x}$-axis with the element $-\pi_{3}{ }^{-}$ $1(\mathrm{k}), \mathrm{k}=1, \ldots, \mathrm{m}$. (See Figure 3.9). 
For each i let $\square(\mathrm{i})$ be the line segment contained in the line $y=i$ determined by the perpendiculars to the $\mathrm{x}$-axis at the two points labelled i. Each $\square(\mathrm{i})$ uniquely determines a square $\mathrm{S}(\mathrm{i})$ with base $\square(\mathrm{i}), \mathrm{i}=1, \ldots, \mathrm{m}$. Notice that $\mathrm{i}<\mathrm{j}$ in $\mathrm{P}(\mathrm{X},<)$ implies:

a) The base $\square(j)$ of $S(j)$ is at least $2 \mathrm{~m}^{2}$ units longer than $\square(i)$.

b) The projection of $\square(\mathrm{j})$ on the $\mathrm{x}$-axis contains the projection of $\square(\mathrm{i})$.

c) $\square(\mathrm{j})$ is at most m-1 units below $\square(\mathrm{i})$.

From a), b) and c) it follows immediately that $S(i)$ is contained in $S(j)$. It is now easy to verify that $\square=\{\mathrm{S}(1), \ldots, \mathrm{S}(\mathrm{m})\}$ is a representation for $\mathrm{P}(\mathrm{X},<)$.

For the general case, instead of using the perpendiculars to the $\mathrm{x}$-axis at the two points labelled $\mathrm{i}$, we use a line forming a $2 \square / \mathrm{n}$ angle with the positive $\mathrm{x}$-axis at the point labelled $\mathrm{i}$ and another line at a (n-2) $\square / n$ angle with the negative $x$-axis at the point labelled $-i$. The points on the $y$-axis should also be repositioned closer to the $\mathrm{x}$-axis.

\subsection{N-gon Orders}

In the last subsection, we studied partial orders arising from families of regular n-gons; in this section, we will study partial orders arising from convex polygons with $n$ sides. Let $\mathrm{P}(\mathrm{X},<)$ be a partial order on $\mathrm{X}=\{1, \ldots, \mathrm{m}\} . \mathrm{P}(\mathrm{X},<)$ is called an $\mathrm{n}$-gon order if there exists a family $\square=\left\{\mathrm{P}_{1}, \ldots, \mathrm{P}_{\mathrm{m}}\right\}$ of convex polygons with $\mathrm{n}$ sides ( $\mathrm{n}$-gons) on the plane such that $\mathrm{x}_{\mathrm{i}}<\mathrm{x}_{\mathrm{j}}$ if polygon $P_{i}$ is contained within $P_{j}$. We will assume that each time two polygons intersect, they cross each other (as we did in the definition of normal families of functions), that no vertex belongs to two different elements of $\square$ and that there are no polygons whose boundaries intersect in a proper line segment . For the case when the elements of $\square=\left\{\mathrm{P}_{1}, \ldots, \mathrm{P}_{\mathrm{m}}\right\}$ are triangles, $\mathrm{P}(\mathrm{X},<)$ is called a triangle order. We can now prove the following result:

Theorem 3.12 [38]: The crossing number of n-gon orders is at most $2 \mathrm{n}$.

Proof: We will prove our result for the case when $\mathrm{P}(\mathrm{X},<)$ is a triangle order. The general case can be easily obtained from this case. We first notice that the boundaries of two different triangles intersect in at most six points. Thus if $\mathrm{P}(\mathrm{X},<)$ has a normal representation, the result follows in the same fashion as in Theorem 3.3. Suppose then that $\mathrm{P}(\mathrm{X},<)$ has a non-normal representation $\square=\left\{P_{1}, \ldots, P_{m}\right\}$. For each triangle $P_{i} \square \square$ let $P_{i}(\square)=\left\{(x, y) \square \mathbb{R}^{2}\right.$ : the euclidian 
distance between $(x, y)$ and $P_{i}$ is smaller than or equal to $\left.\square\right\}$. Then for any two triangles $P_{i}, P_{j} \square$ $\square$ there exists a number $\square$ large enough that $\mathrm{P}_{\mathrm{i}}(\square) \square \mathrm{P}_{\mathrm{j}}(\square) \neq \varnothing$ and the boundaries of $\mathrm{P}_{\mathrm{i}}(\square)$ and $P_{j}(\square)$ intersect in at most six points. Furthermore if $P_{i}$ is contained in $P_{j}$ then $P_{i}(\square)$ is also contained in $\mathrm{P}_{\mathrm{j}}(\square)$. Let $\mathrm{C}$ be a circle of radius $\square$ that contains all the elements of $\square$. Then $\mathrm{P}_{1}(\square) \square \mathrm{P}_{2}(\square) \square \ldots \square \mathrm{P}_{\mathrm{m}}(\square) \neq \varnothing$. Moreover, the boundaries of $\mathrm{P}_{1}(\square), \mathrm{P}_{2}(\square), \ldots, \mathrm{P}_{\mathrm{m}}(\square)$ form closed curves such that any pair of them intersect in at most six points. Using surgery again, we obtain an $\mathrm{f}$-diagram $\square$ for $\mathrm{P}(\mathrm{X},<)$ with crossing number at most six. The proof generalizes easily for $\mathrm{n}$ gons, thus obtaining the desired result.

An immediate consequence of this result is :

Theorem 3.13 [38]: There are partial orders of dimension $2 n+2$ which are not n-gon orders.

Proof: By Theorem 3.2 there are partial orders of dimension $2 n+2$ and crossing number $2 n+1$. Clearly these partial orders cannot be n-gon orders by Theorem 3.12 .

\subsubsection{N-gon Orders and 2n-dimensional Partial Orders}

The main objective of this section is to prove the following result:

Theorem 3.14 [38]: Every poset with dimension $\leq 2 n$ is an $n$-gon poset.

We will need some results before proving this theorem.

Let $\mathrm{P}(\mathrm{X},<)$ be a poset of dimension 2 on the set $\{1, \ldots, \mathrm{m}\}$ and $\left\{\mathrm{L}_{1}\left(\mathrm{X},<_{1}\right), \mathrm{L}_{2}\left(\mathrm{X},<_{2}\right)\right\}$ a realizer of $\mathrm{P}(\mathrm{X},<)$. Then $\mathrm{L}_{1}\left(\mathrm{X},<_{1}\right)$ and $\mathrm{L}_{2}\left(\mathrm{X},<_{2}\right)$ define two permutations $\Pi_{1}=\left\{\pi_{1}(1), \ldots, \pi_{1}(\mathrm{~m})\right\}$ and $\Pi_{2}=\left\{\pi_{2}(1), \ldots, \pi_{2}(m)\right\}$ on $\{1, \ldots, m\}$. Using $\Pi_{1}$ and $\Pi_{2}$ we construct a "caged" representation $\square(\mathrm{P}(\mathrm{X},<))$ of $\mathrm{P}(\mathrm{X},<)$ as follows:

Let $\square(h, k)$ be a rectangle with width $h$, length $k>1$ and sides $S_{1}, S_{2}, S_{3}$ and $S_{4}$. Then a "caged" representation of $\mathrm{P}(\mathrm{X},<)$ is obtained as follows: Divide each of the two opposite sides $\mathrm{S}_{1}, \mathrm{~S}_{3}$ of $\square(\mathrm{h}, \mathrm{k})$ with length $\mathrm{h}$ into $\mathrm{m}+1$ segments of length $\mathrm{h} / \mathrm{m}+1$ using points $\mathrm{p}_{1}, \ldots, \mathrm{p}_{\mathrm{m}}$ in $\mathrm{S}_{1}$ and $\mathrm{q}_{1}, \ldots, \mathrm{q}_{\mathrm{m}}$ in $\mathrm{S}_{3}$. (See Figure 3.10). Place $\pi_{1}(\mathrm{i})$ on $\mathrm{p}_{\mathrm{i}}$ and $\pi_{2}(\mathrm{i})$ on $\mathrm{q}_{\mathrm{i}}, \mathrm{i}=1, \ldots, \mathrm{m}$. Finally if $\pi_{1}(\mathrm{i})$ $=\pi_{2}(\mathrm{j})$ join $\mathrm{p}_{\mathrm{i}}$ to $\mathrm{q}_{\mathrm{j}}$ by a line segment $L\left(\mathrm{p}_{\mathrm{i}}, \mathrm{q}_{\mathrm{j}}\right.$ ). (See Figure 3.10 ). 


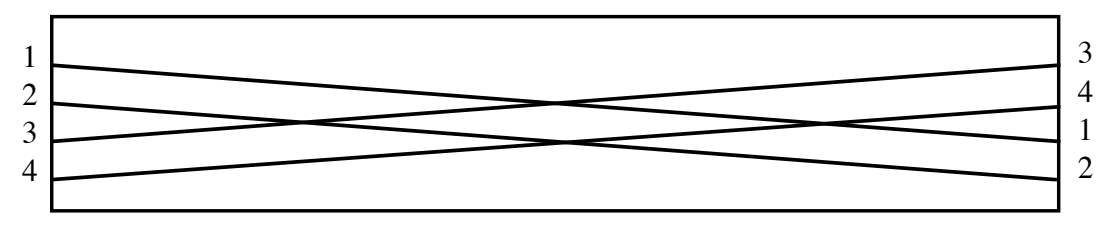

Figure 3.10

Lemma 3.8: Let $\mathrm{p}$ be the intersection point in $\square(\mathrm{h}, \mathrm{k})$ of two line segments $L\left(\mathrm{p}_{\mathrm{i}}, \mathrm{q}_{\mathrm{j}}\right)$ and $L\left(\mathrm{p}_{\mathrm{k}}, \mathrm{q}_{1}\right)$. Then the distance of $\mathrm{p}$ to each of $\mathrm{S}_{1}$ and $\mathrm{S}_{3}$ is at least $\mathrm{k} / \mathrm{m}$.

Proof: The result follows immediately from the fact that the triangles with vertices $\left\{p_{i}, p, p_{k}\right\}$ and the triangle with vertices $\left\{\mathrm{q}_{\mathrm{i}}, \mathrm{p}, \mathrm{q}_{1}\right\}$ are similar, and that the maximum ratio between the distance of $\mathrm{p}_{\mathrm{i}}$ to $\mathrm{p}_{\mathrm{k}}$ and the distance between $\mathrm{q}_{\mathrm{j}}$ and $\mathrm{q}_{\mathrm{l}}$ is at most $\mathrm{m}$.

For example, in Figure 3.10 the distance between $p$ and $S_{1}$ and $S_{3}$ is at least k/4.

Corollary 3.3: If $k \geq 2 \mathrm{~m}$ then the distance between $\mathrm{p}$ and $S_{1}$ and $S_{3}$ is at least 2 .
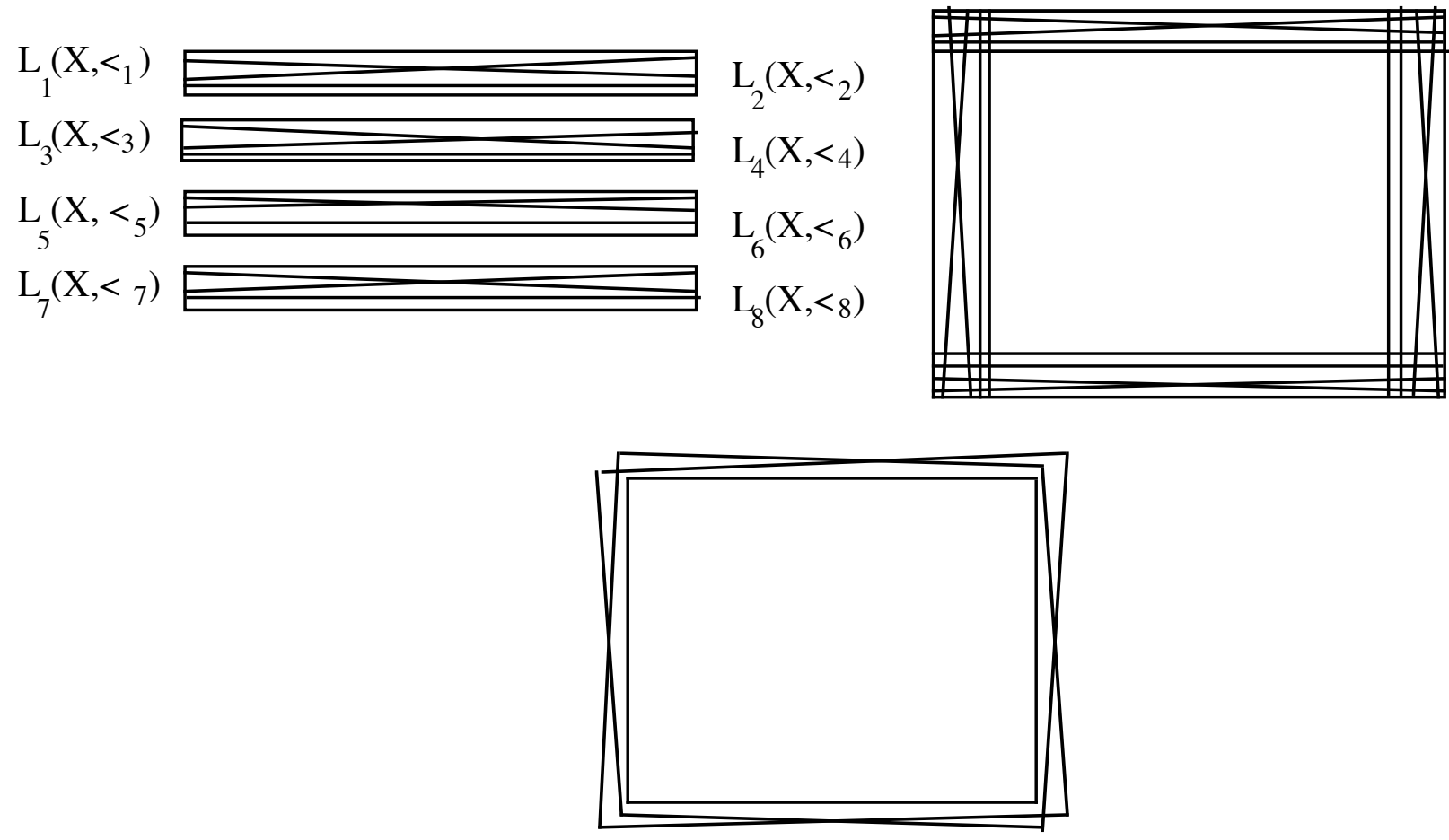

Figure 3.11 
We are now ready to prove Theorem 3.14.

Proof: We carry out the proof for the case $n=4$. For different values of $n$ the proof easily generalizes. Let $\mathrm{P}(\mathrm{X},<)$ be a poset with dimension 8 and $\left\{\mathrm{L}_{1}\left(\mathrm{X},<_{1}\right), \ldots, \mathrm{L}_{8}\left(\mathrm{X},<_{8}\right)\right\}$ be a realizer of $\mathrm{P}(\mathrm{X},<)$. Assume w.l.o.g. that $\mathrm{X}=\{\mathrm{i}, \ldots, \mathrm{m}\}$. Then each $\mathrm{L}_{\mathrm{i}}\left(\mathrm{X},<_{\mathrm{i}}\right)$ defines a permutation $\square_{\mathrm{i}}$ on $\mathrm{X}$, $\mathrm{i}=1, \ldots, 8$. Let $\mathrm{P}_{\mathrm{i}, \mathrm{i}+1}\left(\mathrm{X},<_{\mathrm{i}, \mathrm{i}+1}\right)=\mathrm{L}_{\mathrm{i}}\left(\mathrm{X},<_{\mathrm{i}}\right) \square \mathrm{L}_{\mathrm{i}+1}\left(\mathrm{X},<_{\mathrm{i}+1}\right)$ and $\square\left(\mathrm{P}_{\mathrm{i}, \mathrm{i}+1}\left(\mathrm{X},<_{\mathrm{i}, \mathrm{i}+1}\right)\right)$ be a caged representation using a rectangle with width 1 and length $2 \mathrm{~m}, \mathrm{i}=1,3,5,7$. Let $\square_{4}$ be a square on the plane with sides labelled $\square_{1}, \square_{3}, \square_{5}, \square_{7}$ of length $2 \mathrm{~m}$. Place $\square\left(\mathrm{P}_{\mathrm{i}, \mathrm{i}+1}\left(\mathrm{X},<_{\mathrm{i}, \mathrm{i}+1}\right)\right)$ in the interior of $\square_{4}$ in such a way that the top of $\square\left(P_{i, i+1}\left(X,<_{i, i+1}\right)\right)$ lies on $\square_{i}, i=1,3,5,7$ (See Figure 3.11). For each $\mathrm{x} \square \mathrm{X}$ there is a segment $L_{\mathrm{i}}(\mathrm{x})$ in $\square\left(\mathrm{P}_{\mathrm{i}, \mathrm{i}+1}\left(\mathrm{X},<_{\mathrm{i}, \mathrm{i}+1}\right)\right), \mathrm{i}=1,3,5,7$. If we take $\mathrm{C}(\mathrm{x})=L_{1}(\mathrm{x}) \square L_{3}(\mathrm{x}) \square L_{5}(\mathrm{x}) \square L_{7}(\mathrm{x})$ it divides the plane into two regions one of which (the interior of $\mathrm{C}(\mathrm{x})$ ) is the interior of an $\mathrm{n}-\mathrm{gon} \mathrm{N}(\mathrm{x})$; $\mathrm{x} \square \mathrm{X}$. Since $\mathrm{P}(\mathrm{X},<)=\mathrm{P}_{1,2}\left(\mathrm{X},<_{1,2}\right) \square \mathrm{P}_{3,4}\left(\mathrm{X},<_{3,4}\right) \square \mathrm{P}_{5,6}\left(\mathrm{X},<_{5,6}\right) \square \mathrm{P}_{7,8}\left(\mathrm{X},<_{7,8}\right)$, it now follows that $\mathrm{N}(\mathrm{x})$ is contained in $\mathrm{N}(\mathrm{x})$ iff $\mathrm{x}<\mathrm{y}$ in $\mathrm{P}(\mathrm{X},<)$.

When the dimension of $\mathrm{P}(\mathrm{X},<)$ is 4 , we have two caged representations $\square\left(\mathrm{P}_{1,2}\left(\mathrm{X},<_{1,2}\right)\right)$ and $\square\left(\mathrm{P}_{3,4}\left(\mathrm{X},<_{3,4}\right)\right)$ of $\mathrm{L}_{1}\left(\mathrm{X},<_{1}\right) \square \mathrm{L}_{1}\left(\mathrm{X},<_{1}\right)$ and $\mathrm{L}_{1}\left(\mathrm{X},<_{1}\right) \square \mathrm{L}_{1}\left(\mathrm{X},<_{1}\right)$ respectively. In this case, using only two adjacent sides of our square and properly respacing the elements $\mathrm{p}_{\mathrm{i}}$ and $\mathrm{q}_{\mathrm{i}}$ in $\square\left(\mathrm{P}_{1,2}\left(\mathrm{X},<_{1,2}\right)\right)$ and $\square\left(\mathrm{P}_{3,4}\left(\mathrm{X},<_{3,4}\right)\right), \mathrm{i}=1, \ldots \mathrm{n}$, we obtain angle orders [13].

We proved that all posets with dimension $2 \mathrm{n}$ are $\mathrm{n}$-gon orders and that there are posets of dimension $2 n+2$ which are not $n$-gon orders. For posets with dimension $2 n+1$ the following problem was posed in [38]:

Problem 3.2. Are there are posets with dimension $2 n+1$ which are not $n$-gon orders?

In a recent paper, Alon and Scheinerman [1] showed that there are partial orders of dimension $2 n+1$ which are not $n$-gon orders thus solving Problem 3.2. The proof given in [1], however, uses a counting argument and does not produce an specific family of posets of dimension $2 n+1$ not $n$ gon orders. It would still be of interest to find specific families of $2 n+1$ posets which are not $n$ gon orders.

\subsection{Angle Orders}

We now proceed to study representations of partial orders using families of angular regions. 
Angle orders were introduced in Fishburn and Trotter [13]. An angular region is a closed region A of $\mathbb{R}^{2}$ bounded by a pair of rays $R_{1}$ and $R_{2}$ emanating from a point $p$ containing all points swept out by rays from $p$ in the clockwise direction from $R_{1}$ to $R_{2}$. A poset $P(X,<)$ is called an angle order if it has a representation using angular regions in the plane. In [13] it was proved that all posets of dimension at most four are angle orders. Moreover, in the same paper it was proved that the poset consisting of all elements $\mathrm{x} \square 2^{7}$ (under containment) with at most four elements is not an angle order (this poset has 198 elements). The following questions were posed in [13]:

Problem 3.3: What is the dimension of the least dimension poset which is not an angle order?

Problem 3.4: Is $2^{5}$ an angle order? And in general what is the smallest $n$ such that $2^{n}$ is not an angle order?

In the rest of this section, we shall produce a poset of dimension 6 with 64 elements which is not an angle order. Thus Problem 3.2 reduces to the following: Are all posets of dimension 5 angle orders? The problem of deciding if $2^{5}$ is an angle order remains open. The technique used to prove our results follows some ideas presented in [13] combined with the crossing number of posets.

Let $A$ be an angular region bounded by two rays $R_{1}$ and $R_{2}$. If the angle between $R_{1}$ and $R_{2}$ is less than $180^{\circ}$, $\mathrm{A}$ is called a little angle; if the angle exceeds $180^{\circ}$, A will be called a big angle. The point $p$ will be called the vertex of $A$. Notice that if the angle between $R_{1}$ and $R_{2}$ is $180^{\circ}$ then the vertex of $\mathrm{A}$ is not unique.

An angle order $\mathrm{P}(\mathrm{X},<)$ that has a representation using only little angles will be called an $l$ angle order. If $\mathrm{P}(\mathrm{X},<)$ has a representation using only big angles, $\mathrm{P}(\mathrm{X},<)$ will be called a $b$-angle order.

For a given angular region $\mathrm{A}$ in the plane let $\mathrm{A}^{*}=\mathbb{R}^{2}-\mathrm{A}$. Clearly if $\mathrm{A}$ is a little angular region, $A^{*}$ is a big angular region. The next result follows immediately from observations made in [13].

Lemma 3.9 [13]: If $\mathrm{P}(\mathrm{X},<)$ is an l-angle (b-angle ) order, then the dual $\mathrm{P}^{*}(\mathrm{X},<)$ of $\mathrm{P}(\mathrm{X},<)$ is a b-angle (1-angle) order.

Proof: Let $\mathrm{R}=\left\{\mathrm{A}_{1}, \ldots, \mathrm{A}_{\mathrm{n}}\right\}$ be a representation of $\mathrm{P}(\mathrm{X},<)$ using little (big) angular regions. Then $\mathrm{R}^{*}=\left\{\mathrm{A}^{*}{ }_{1}, \ldots, \mathrm{A}^{*}{ }_{\mathrm{n}}\right\}$ is a representation for $\mathrm{P}^{*}(\mathrm{X},<)$ using big (little) angular regions. 
Next, we observe that the boundaries of two different angular regions intersect in at most four points. This lead us to the following result:

Lemma 3.10 [32]: The crossing number of an 1-angle order is at most 4.

Proof: Let $\mathrm{R}=\left\{\mathrm{A}_{1}, \ldots, \mathrm{A}_{\mathrm{n}}\right\}$ be a representation of $\mathrm{P}(\mathrm{X},<)$ using little angular regions. Assume without loss of generality that all the intersection points of the boundaries of the angular regions of $\mathrm{R}$ are contained in a circle of radius 1 with center in the origin.

Let us assume that $\mathrm{x}_{1}<\mathrm{x}_{2}<\ldots<\mathrm{x}_{\mathrm{n}}$ is a linear extension of $\mathrm{P}(\mathrm{X},<)$. For each element $\mathrm{x}_{\mathrm{i}} \square \mathrm{X}$ let $\mathrm{S}_{\mathrm{i}}$ be the region determined by the intersection of $A_{i}$ with the circle of radius $i$ and center in the origin. Clearly $x_{i}<x_{j}$ if and only if $S_{i}$ is contained in $S_{j}, i \neq j \square\{1, \ldots, n\}$. Let $S_{i}(1)$ be the set of points in $\mathbb{R}^{2}$ at distance $\leq 1$ from $S_{i}$. Since the origin belongs to $S_{i}(1), i=1, \ldots, n, S_{1} \square \ldots \square S_{n} \neq \varnothing$. Moreover, the boundaries of any two such sets intersect in at most four points. Let $\mathrm{L}_{0}$ be a ray emanating from the origin that does not meet any point in which the boundaries of any two elements $S_{i}(1), S_{j}(1)$ intersect. Using surgery again as in Lemma 3.4, our result follows.

Lemma 3.11 [32]: The crossing number of a b-angle order is at most 4.

Proof: By Lemma 3.9 the dual $\mathrm{P}^{*}(\mathrm{X},<)$ of an angle order $\mathrm{P}(\mathrm{X},<)$ is an 1-angle order. Thus the crossing number of $\mathrm{P}^{*}(\mathrm{X},<)$ is at most 4 . But the crossing number of a poset is equal to the crossing number of its dual. The result now follows .

The next result trivially follows:

Lemma 3.12 [32]: Let $\mathrm{P}(\mathrm{X},<)$ be a poset with crossing number greater than or equal to 5 . Then if $\mathrm{P}(\mathrm{X},<)$ is an angle order, any representation $\mathrm{R}=\left\{\mathrm{A}_{\mathrm{i}}, \ldots, \mathrm{A}_{\mathrm{i}}\right\}$ of $\mathrm{P}(\mathrm{X},<)$ contains a little and a big angular region.

Theorem 3.15 [32]: There are posets of dimension 6 which are not angle orders.

Proof: The idea used in the proof of this theorem is similar to the one used by Fishburn and Trotter in their proof of Corollary 2 in [13]. Let $\mathrm{P}(\mathrm{X},<)$ be any poset with crossing number at least 5. Let us construct a new poset $Q$ consisting of two isomorphic copies $P_{1}(X,<), P_{2}(X,<)$ of 
$\mathrm{P}(\mathrm{X},<)$ such that if $\mathrm{x} \square \mathrm{P}_{1}(\mathrm{X},<)$ and $\mathrm{y} \square \mathrm{P}_{2}(\mathrm{X},<)$ then $\mathrm{x}<\mathrm{y}$. We claim that $\mathrm{Q}$ is not an angle order. For if $\mathrm{Q}$ is an angle order, then there is a representation $\mathrm{R}$ of $\mathrm{Q}$ using angular regions in the plane. By Lemma 3.12, there is a big angular region $A_{i}$ representing an element $x_{i} \square P_{1}(X,<)$. Similarly there is a small region $B_{j}$ representing an element $y_{j} \square P_{2}(X,<)$. However, since by definition $x_{i}<$ $y_{j}, A_{i}$ is contained in $B_{j}$ which is impossible. Letting $P(X,<)=\square_{6}$ gives us the desired result.

Since $\square_{6}$ has $12+\mathrm{C}(6,3)$ elements, Theorem 3.15 gives us a poset with 64 elements which is not an angle order. Some open problems are now presented. We proved that the crossing number of 1-angle orders and b-angle orders is at most 4 . This leads us to the following question:

Is it true that the crossing number of angle orders is at most 4? More specifically, is $\square_{6}$ an angle order? So far we have been unable to verify whether $\square_{6}$ is an angle order or not.

What about partial orders with crossing number $\leq 4$; is it true that any partial order with crossing number at most 4 is an angle order?

Similar questions can be asked about regular n-gon orders. For instance, is it true that all partial orders with crossing number 2 are regular n-gon orders for some $n$ ?

W.T. Trotter has pointed out that Problem 3.3 can be solved using the argument used here. Problem 3.3 can be solved by observing that the boundaries of any two little angles, containing a third one, intersect at most 3 times. Thus the crossing number of an 1-angle order with a 0 element is at most 3. We can now apply the same techniques as in Theorem 3.15 to obtain the desired result. Thus we have:

Theorem 3.16: There are partial orders of dimension 5 which are not angle orders.

\subsection{Comparability Graph Invariants}

An undirected graph $\mathrm{G}=(\mathrm{V}, \mathrm{E})$ is called a comparability graph if there exists an orientation $\mathrm{D}$ of the edges of $\mathrm{G}$ in which $\mathrm{x} \square \mathrm{y}$ and $\mathrm{y} \square \mathrm{z}$ imply $\mathrm{x} \square \mathrm{z}$. A transitive orientation $\mathrm{D}$ of $\mathrm{G}$ produces a partial order in $\mathrm{P}(\mathrm{V},<)$ in which $\mathrm{u}<\mathrm{v}$ in $\mathrm{P}(\mathrm{V},<)$ if $\mathrm{u} \square \mathrm{v} \square \mathrm{D}$. A comparability graph $\mathrm{G}$ may admit many different transitive orientations, each of which produces a different partial order on $\mathrm{V}$. A property $\mathrm{Q}$ is called a comparability graph invariant if $\mathrm{Q}$ is satisfied by all partial orders on $\mathrm{V}$ obtained from transitive orientations of G. A well-known comparability graph invariant is, for example, the dimension of G. One geometrical "invariant" of a comparability graph is "interval 
order", that is;

Theorem 3.17: Let $G$ be a comparability graph such that a transitive orientation $D$ of $G$ produces an interval order on $\mathrm{V}(\mathrm{G})$. Then any transitive orientation $\mathrm{D}^{\prime}$ of G produces an interval order on $V(G)$.

An easy consequence of Theorems 3.4, 3.5, 3.9 and 3.10 and the decomposition theorem for comparability graphs is the next result:

Theorem 3.18 [40]: Let $G$ be a comparability graph such that a transitive orientation $D$ of $G$ is a circle order (regular n-gon order). Then any transitive orientation of $\mathrm{G}$ produces a circle order (regular n-gon order) on $\mathrm{V}$.

Similarly we can prove:

Theorem 3.19 [40]: The crossing number of a partial order is a comparability graph invariant.

\subsection{Some Open Problems}

Let $\square$ and $\square$ be families of orders such that $\square \mathrm{P}(\mathrm{X},<)) \leq \mathrm{m}$ and $\square(\mathrm{Q}(\mathrm{Y},<)) \leq \mathrm{n}$ for $\mathrm{P}(\mathrm{X},<) \square \square$ and $\mathrm{Q}(\mathrm{Y},<) \square \square ; \mathrm{m}<\mathrm{n}$. It is obvious that if $\mathrm{Q}(\mathrm{Y},<) \square \square$ exists for which $\square(\mathrm{Q}(\mathrm{Y},<))=\mathrm{n}$ then $\square$ is not contained in $\square$. A natural question arises: When is $\square$ contained in $\square$ ?

For instance it is not very hard to show that the crossing number of interval orders is at most 2. We also known that there are angle orders with crossing number greater than 2 . Then there are angle orders which are not circle orders. In the case of interval orders and angle orders the following result is known:

Theorem 3.20 [13]. Every interval order is an angle order.

In a recent paper P. Fishburn proved the following result:

Theorem 3.21 [12] Every interval order is a circle order.

Two questions remain open: 
Problem 3.5. Is it true that every circle order (crossing number at most 2) is an n-gon (regular n-gon) order?

Problem 3.6. Is every circle order an angle order?

\section{RELATED RESULTS ON POINTS AND CIRCLES}

A complete characterization of circle orders seems at this point to be very hard to obtain. For this reason we studied a much simpler version of the above-mentioned problem, namely: What partial orders are circle orders representable using circles of two different sizes?

It is easy to see that in this case, the problem is equivalent to studying containment relations among families of points and circles (all of the same radius) on the plane. For let $\square=\left\{\mathrm{C}_{1}, \ldots, \mathrm{C}_{\mathrm{m}}\right\}$ be a circle diagram in which $C_{1}, \ldots, C_{i}$ have radius $a$ and $C_{i}, \ldots, C_{m}$ have radius $b, a<b$. Then if we reduce the radii of all the elements of $\square$ by a, $C_{1}, \ldots, C_{i}$ will become points and $C_{i}, \ldots, C_{m}$ become circles of radius b-a.

This led us to study the general problem of containment relations among families of points and circles. In this section, our aim is to prove the following result as well as some results related to it.

Theorem 4.1 [27]: For any collection $P_{n}$ of $n$ points on the plane, there exists a pair of points $\mathrm{u}_{\mathrm{o}}, \mathrm{v}_{\mathrm{o}}$ such that any circle containing them contains at least (n-2)/60 points of $\mathrm{P}_{\mathrm{n}}$.

Some notation and definitions will be needed to prove this result. A graph $G=(V(G), E(G))$ consists of a collection of points $V(G)$ called the vertices of $G$ and a set $E(G)$ of unordered pairs of elements of $\mathrm{V}(\mathrm{G})$ called the edges of $\mathrm{G}$. If the pair $\{\mathrm{u}, \mathrm{v}\}$ belongs to $\mathrm{E}(\mathrm{G})$, we say that $\mathrm{u}$ and $\mathrm{v}$ are adjacent. An edge $\{\mathrm{u}, \mathrm{v}\}$ will be denoted by $\mathrm{u}-\mathrm{v}$. We say that $\mathrm{u}-\mathrm{v}$ joins $\mathrm{u}$ to $\mathrm{v}$. A complete graph $K_{n}$ is a graph with $n$ vertices such that for any pair of vertices $u, v$ of $V\left(K_{n}\right)$, $\mathrm{u}-\mathrm{v}$ is an edge of $\mathrm{K}_{\mathrm{n}}$. For a pair of points $\mathrm{u}$ and $\mathrm{v}$ on the plane let $\mathrm{l}(\mathrm{u}, \mathrm{v})$ be the open segment of line joining $\mathrm{u}$ to $\mathrm{v}$. The following lemma will prove useful.

Lemma 4.1 [27]: Let $u, v, x, y$ be points in the plane such that $1(u, v)$ and $1(x, y)$ intersect. Then any circle containing $\mathrm{u}$ and $\mathrm{v}$ contains at least one end point of $1(\mathrm{x}, \mathrm{y})$ or any circle containing $\mathrm{x}$ and $\mathrm{y}$ contains at least one end point of $\mathrm{l}(\mathrm{u}, \mathrm{v})$. 
Proof: It is easy to see that $\mathrm{u}, \mathrm{v}, \mathrm{x}$ and $\mathrm{y}$ form the vertices of a convex quadrilateral. (See Figure 4.1).

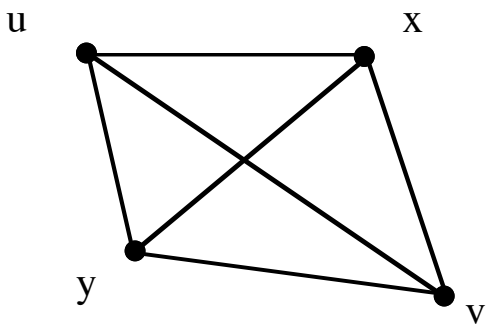

Figure 4.1

In any such quadrilateral there exist two internal opposite angles such that their sum is greater than or equal to $180^{\circ}$. Without loss of generality let us assume that it is the angles of $\mathrm{u}$ and $\mathrm{v}$ that satisfy this property. Then any circle containing $\mathrm{x}$ and $\mathrm{y}$ contains at least one of $\mathrm{u}$ or $\mathrm{v}$.

Let $\mathrm{P}_{\mathrm{n}}$ be a collection of $\mathrm{n}$ points on the plane. An imbedding of $\mathrm{K}_{n}$ on the plane can be obtained by representing the vertices of $K_{n}$ with the points of $P_{n}$ and the edges of $K_{n}$ with the segments $1(\mathrm{u}, \mathrm{v}), \mathrm{u} \neq \mathrm{v} ; \mathrm{u}, \mathrm{v} \square \mathrm{P}_{\mathrm{n}}$.

Let us define $I\left(P_{n}\right)$, the intersection number of $P_{n}$ as follows: $I\left(P_{n}\right)$ is the number of different segments $1(\mathrm{u}, \mathrm{v}), \mathrm{l}(\mathrm{x}, \mathrm{y})$ such that $\mathrm{l}(\mathrm{u}, \mathrm{v}) \square \mathrm{l}(\mathrm{x}, \mathrm{y}) \neq \varnothing ; \mathrm{u}, \mathrm{v}, \mathrm{x}, \mathrm{y} \square \mathrm{P}_{\mathrm{n}}$.

Lemma 4.2 [27]: $I\left(P_{n}\right) \geq C(n, 5) /(n-4)$.

Proof: Since $\mathrm{K}_{5}$ is not a planar graph, for each subset $\mathrm{S}$ of $\mathrm{P}_{\mathrm{n}}$ with exactly five elements, there exist four points $\mathrm{u}, \mathrm{v}, \mathrm{x}, \mathrm{y} \square \mathrm{S}$ such that $\mathrm{l}(\mathrm{u}, \mathrm{v}) \square \mathrm{l}(\mathrm{x}, \mathrm{y}) \neq \varnothing$. Furthermore, the subset $\{\mathrm{u}, \mathrm{v}, \mathrm{x}, \mathrm{y}\}$ appears in exactly $n-4$ subsets of $P_{n}$ with five elements.

Finally, let us define a graph $\mathrm{G}\left(\mathrm{P}_{\mathrm{n}}\right)$ (the intersection graph of $\mathrm{P}_{\mathrm{n}}$ ) as follows: $\mathrm{V}\left(\mathrm{G}\left(\mathrm{P}_{\mathrm{n}}\right)\right)=\left\{\mathrm{l}(\mathrm{u}, \mathrm{v}) ; \mathrm{u}, \mathrm{v} \square \mathrm{P}_{\mathrm{n}}, \mathrm{u} \neq \mathrm{v}\right\}$ and two vertices $\mathrm{l}(\mathrm{u}, \mathrm{v}), \mathrm{l}(\mathrm{x}, \mathrm{y})$ of $\mathrm{G}\left(\mathrm{P}_{\mathrm{n}}\right)$ are adjacent if $1(\mathrm{u}, \mathrm{v}) \square 1(\mathrm{x}, \mathrm{y}) \neq \varnothing$. (See Figure 4.2). 

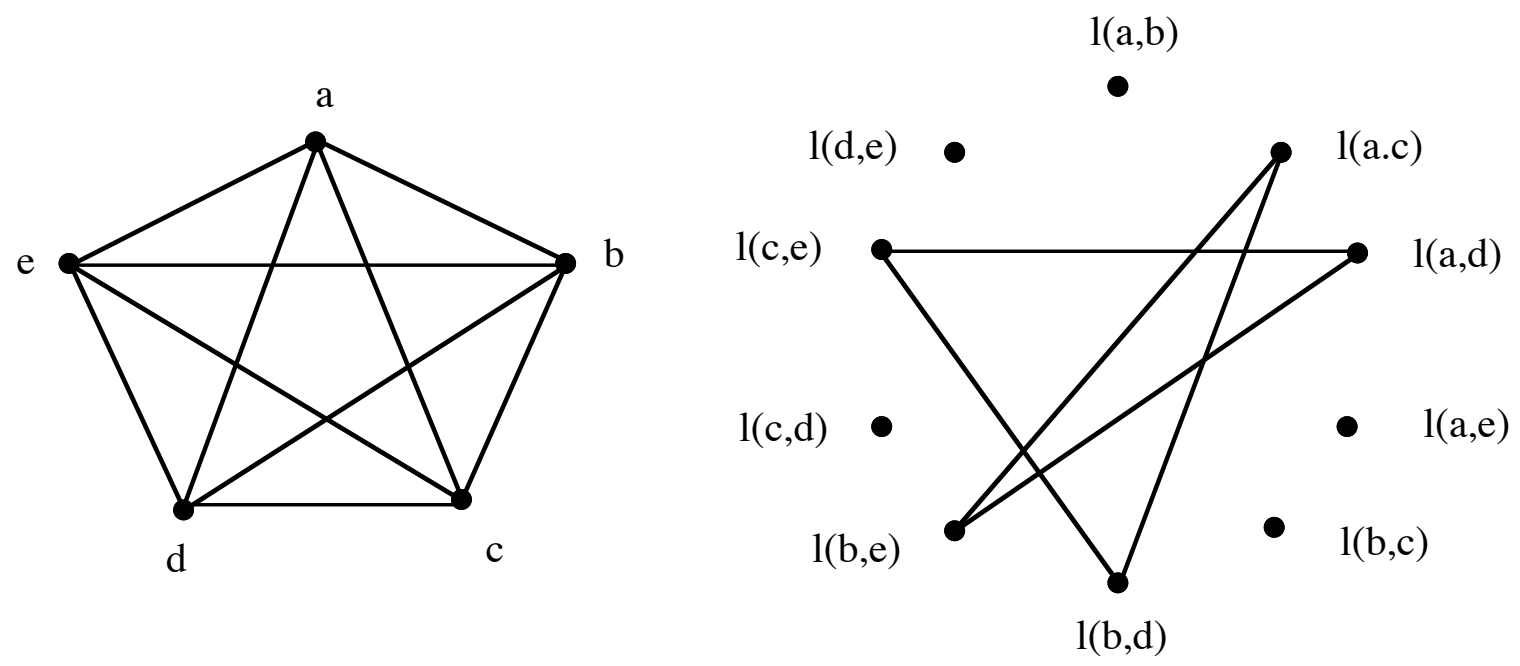

Figure 4.2

Clearly $G\left(P_{n}\right)$ has exactly $I\left(P_{n}\right)$ edges, one for each pair of intersecting segments $1(u, v), 1(x, y)$.

Corollary 4.1 [27]: $\left|\mathrm{E}\left(\mathrm{G}\left(\mathrm{P}_{\mathrm{n}}\right)\right)\right| \geq \mathrm{C}(\mathrm{n}, 5) /(\mathrm{n}-4)$.

We now obtain an orientation $\mathrm{D}\left(\mathrm{P}_{\mathrm{n}}\right)$ of $\mathrm{G}\left(\mathrm{P}_{\mathrm{n}}\right)$ as follows: An edge $\mathrm{l}(\mathrm{u}, \mathrm{v})-\mathrm{l}(\mathrm{x}, \mathrm{y})$ is oriented $1(\mathrm{u}, \mathrm{v}) \square \mathrm{l}(\mathrm{x}, \mathrm{y})$ if any circle containing $\mathrm{u}$ and $\mathrm{v}$ contains $\mathrm{x}$ or $\mathrm{y}$, otherwise we orient $1(x, y) \square 1(u, v)$. This orientation is consistent because of Lemma 4.1. We should notice that if $u$, $\mathrm{v}, \mathrm{x}$ and $\mathrm{y}$ lie on a circle, then we could choose either orientation; $1(\mathrm{u}, \mathrm{v}) \square 1(\mathrm{x}, \mathrm{y})$ or $1(x, y) \square 1(u, v)$. Let $d^{+}(u)$ be the out-degree of a vertex $u$ in a directed graph $D$, ie. the number of vertices $x$ such that $\mathrm{u} \square \mathrm{x} \square \mathrm{E}(\mathrm{D})$.

Lemma 4.3 [27]: There exists a vertex $1\left(\mathrm{u}_{\mathrm{o}}, \mathrm{v}_{\mathrm{o}}\right) \square \mathrm{V}\left(\mathrm{G}\left(\mathrm{P}_{\mathrm{n}}\right)\right)$ such that $\mathrm{d}^{+}\left(1\left(\mathrm{u}_{\mathrm{o}}, \mathrm{v}_{\mathrm{o}}\right)\right) \geq(\mathrm{n}-2)(\mathrm{n}-$ $3) / 60$.

Proof: From Corollary 4.1, $\left|\mathrm{E}\left(\mathrm{G}\left(\mathrm{P}_{\mathrm{n}}\right)\right)\right| \geq \mathrm{C}(\mathrm{n}, 5) /(\mathrm{n}-4)$. We also know that $\sum \mathrm{d}^{+}(1(\mathrm{u}, \mathrm{v}))=\left|\mathrm{E}\left(\mathrm{G}\left(\mathrm{P}_{\mathrm{n}}\right)\right)\right|$. Then $\sum \mathrm{d}^{+}(1(\mathrm{u}, \mathrm{v})) \geq \mathrm{C}(\mathrm{n}, 5) /(\mathrm{n}-4)$. Since we have exactly $\mathrm{C}(\mathrm{n}, 2)$ vertices in $\mathrm{G}\left(\mathrm{P}_{\mathrm{n}}\right)$, there exists a vertex $1\left(\mathrm{u}_{\mathrm{o}}, \mathrm{v}_{\mathrm{o}}\right)$ with $\mathrm{d}^{+}\left(1\left(\mathrm{u}_{\mathrm{o}}, \mathrm{v}_{\mathrm{o}}\right)\right) \geq[\mathrm{C}(\mathrm{n}, 5) /(\mathrm{n}-4)] / \mathrm{C}(\mathrm{n}, 2)=(\mathrm{n}-2)(\mathrm{n}-3) / 60$.

We can now prove Theorem 4.1.

Proof of Theorem 4.1: By Lemma 4.3, there exist two points, $\mathrm{u}_{\mathrm{o}}, \mathrm{v}_{\mathrm{o}}$ in $\mathrm{P}_{\mathrm{n}}$ such that 
$d^{+}\left(1\left(u_{o}, v_{o}\right)\right) \geq(n-2)(n-3) / 60$. Then there exist at least (n-2)(n-3)/60 segments $1(x, y), x, y \square P_{n}$ such that any circle containing $\mathrm{u}_{\mathrm{o}}$ and $\mathrm{v}_{\mathrm{o}}$ contains one end point of each one of these segments. Eliminating redundancies (no point $\mathrm{x}$ different from $\mathrm{u}_{\mathrm{o}}$ and $\mathrm{v}_{\mathrm{o}}$ can belong to more than $\mathrm{n}-3$ line segments) we obtain the desired result.

In Lemma 4.3, we showed that there exists a vertex $1(u, v)$ in $D\left(P_{n}\right)$ with $d^{+}(1(u, v)) \geq(n-2)(n-$ 3)/60. Using the same arguments as for Lemma 4.3, we can obtain the following corollary.

Corollary 4.2 [27]: The average out-degree $d^{+}(1(u, v)), 1(u, v) \square V\left(D\left(P_{n}\right)\right)$ is greater than or equal to $(n-2)(n-3) / 60$.

For a pair of points $u, v \square P_{n}$, let $C(u, v)$ be the minimum number of points of $P_{n}$ that are contained in any circle containing $u$ and $v$. Let $A\left(P_{n}\right)$ be the average over all $C(u, v), u, v \square P_{n}$. A result which is much stronger than Theorem 4.1 now follows:

Theorem 4.2 [27]: $A\left(P_{n}\right) \geq(n-2) / 60$.

Theorem 4.1 was later improved by R. Hayward, D. Rappaport and R. Wegner [22]. They proved that $A\left(P_{n}\right) \geq n / 27$. R. Hayward has improved this result even further; in a very nice way he proved:

Theorem 4.3 [21]: For any collection $P_{n}$ of $n$ points on the plane, there exists a pair of points $\mathrm{u}_{\mathrm{o}}, \mathrm{v}_{\mathrm{o}}$ such that any circle containing them contains at least $\bar{\sigma}(\mathrm{n}-2) / 84 \square$ points of $\mathrm{P}_{\mathrm{n}}$.

Theorem 4.2 was recently improved and generalized to higher dimensions. The next result, given without proof, is proved in [2]. Let $r=n+3, m=\square n+3 \square 2$ and $c_{n}=[m !(r-m+1) !] / r !$.

Theorem 4.4 [2]: For each $n \geq 1$ there is $c_{n}>0$ such that for any finite set $X$ of $\mathbb{R}^{n}$ there is a subset $A$ of $X$ of cardinality $|A| \leq(n+3) / 2$ such that any $n$-ball $B$ containing A contains at least $c_{n} \cdot|X|$ elements of $X$.

This result seems to be optimal in a strong way. Let $B(t)=\left(t, t^{2}, \ldots, t^{n}\right)$ and $P_{m}=\left\{ß\left(t_{i}\right)\right.$; $\left.0<\mathrm{t}_{1}<\mathrm{t}_{2}<\ldots<\mathrm{t}_{\mathrm{m}}\right\} . \beta(\mathrm{t})$, called the momentum curve, was first discovered by Carathéodory [5], [6]. In [17] (pages 61- 62) the following result is proved: 
Theorem 4.5: For any k-pointed subset $A$ of $P_{m}, k \leq \square(n+3) / 2 \square$ there exists a supporting hyperplane $\mathrm{H}$ of the convex hull of $\mathrm{P}_{\mathrm{m}}$ such that $\mathrm{H} \square \mathrm{P}_{\mathrm{n}}=\mathrm{A}$.

As a consequence of this result, we can easily prove the following:

Theorem 4.6 [27]: For any subset $A$ of $P_{m}$ with $|A| \leq \square(n+1) / 2 \square$ there exists a 2d-dimensional sphere $S(A)$ containing all elements of $A$ such that $S(A) \square P_{n}=A$.

An interesting subproblem occurs when the elements of $P_{n}$ are the vertices of a convex polygon. The next result was proved in [27]:

Theorem 4.7 [27]: Let $P_{n}$ be the vertices of a convex polygon. Then there exist two vertices $u$ and $v$ of $P_{n}$ such that any circle containing them contains at least (n-2)/4 elements of $P_{n}$.

In the same paper the following problem was stated:

Problem 4.1: Show that in any convex polygon $\mathrm{P}$ with $\mathrm{n}$ vertices, there exist two opposite vertices $\mathrm{u}$ and $\mathrm{v}$ such that any circle containing them contains at least half of the vertices of $\mathrm{P}$.

In [22] it was proved that the bounds stated in Problem 4.1 were incorrect. The next results were proved:

Theorem 4.8 [22]: Let $P_{n}$ be the vertices of a convex polygon. Then there exist two vertices $u$ and $v$ of $P_{n}$ such that any circle containing them contains at least $n / 3$ elements of $P_{n}$. This is best possible.

J. Schmerl proved the following result independently:

Theorem 4.9 [37]: Let $\mathrm{P}$ be a convex (3n+1)-gon. Then there exist two vertices $\mathrm{u}$ and $\mathrm{v}$ of $P$ such that any circle containing them contains at least $n+2$ vertices of $P$.

Proof: Let $X$ be the set of vertices of P. For $x, y, X$, let $(x, y)$ be the points of $X$ between $\mathrm{x}$ and $\mathrm{y}$ (in the counterclockwise direction). If there are $\mathrm{u}, \mathrm{v} \square \mathrm{X}$ and a circle $\mathrm{C}$ through $u$ and $v$ such that $X$ is contained in $C$ and such that $|(u, v)| \geq n$ and $|(v, u)| \geq n$, then we are done, as any circle through $\mathrm{u}$ and $\mathrm{v}$ will contain either $(\mathrm{u}, \mathrm{v})$ or $(\mathrm{v}, \mathrm{u})$ as a subset. 
Choose $\mathrm{u}, \mathrm{v} \square \mathrm{X}$ and circle $\mathrm{C}$ through $\mathrm{u}$ and $\mathrm{v}$ containing $\mathrm{X}$ such that $|(\mathrm{u}, \mathrm{v})|<|(\mathrm{v}, \mathrm{u})|$ and $|(v, u)|$ is minimal. Clearly $|(v, u)| \geq 2 n$ (for otherwise $|(u, v)| \geq n$ and we are done). Therefore there is $\mathrm{w} \square(\mathrm{v}, \mathrm{u})$ and a circle $\mathrm{C}$ through $\mathrm{u}, \mathrm{v}, \mathrm{w}$ containing $\mathrm{X}$. Without loss of generality, suppose $\mid(\mathrm{v}, \mathrm{w}) \mathrm{I} \geq \mathrm{n}$, so $\mid(\mathrm{w}, \mathrm{v}) \mathrm{|}$. But this implies $|(\mathrm{w}, \mathrm{v})|<\mathrm{l}(\mathrm{v}, \mathrm{w})|<|(\mathrm{v}, \mathrm{u}) \mid$, contradicting the minimality of $|(\mathrm{v}, \mathrm{u})|$.

\subsection{Generalization of Points and Circles}

A natural question arises from Theorems 4.1 and 4.2, namely: Is Theorem 4.1 or 4.2 a characterization of the circle?

Formally speaking, given a closed curve $S$, we denote by $\square(S)$ the set of all curves on the plane homotopic to $S$ (for instance if $E[a, b]$ is an ellipse with minor and major axis a and $b$ respectively, then $\square(\mathrm{E})$ is the set of all ellipses $\mathrm{E}^{\prime}[\mathrm{x}, \mathrm{y}]$ with minor and major axis $\mathrm{x}$ and $\mathrm{y}$ respectively such that $\mathrm{x} / \mathrm{y}=\mathrm{a} / \mathrm{b})$.

Let $\mathrm{P}_{\mathrm{n}}$ be a collection of points on the plane, $\mathrm{u}, \mathrm{v} \square \mathrm{P}_{\mathrm{n}}$. We define $\mathrm{S}(\mathrm{u}, \mathrm{v})$ to be the minimum number of elements of $P_{n}$ (different from $u$ and v) contained within any curve $S^{\prime} \square \square(S)$ containing $\mathrm{u}$ and $\mathrm{v}$. Thus if $\mathrm{S}$ is a square, $\mathrm{S}(\mathrm{u}, \mathrm{v})$ is obtained by finding a square containing $\mathrm{u}$ and $v$ which contains as few points of $P_{n}$ as possible. When $\mathrm{C}$ is a circle, $\mathrm{C}(\mathrm{u}, \mathrm{v})$ coincides with the definition of $\mathrm{C}(\mathrm{u}, \mathrm{v})$ given before Theorem 4.2. Finally, we define $\mathrm{A}\left(\mathrm{S}, \mathrm{P}_{\mathrm{n}}\right)$ to be the average value of $S(u, v)$ taken over all pairs $\{\mathrm{u}, \mathrm{v}\}$ contained in $\mathrm{P}_{\mathrm{n}}$.

Theorems 4.1 and 4.2 could now be restated as follows:

Theorem 4.1': For any collection $\mathrm{P}_{\mathrm{n}}$ of $\mathrm{n}$ points on the plane, there exists a pair of points $\mathrm{u}_{\mathrm{o}}$, $\mathrm{v}_{\mathrm{o}}$ such that $\mathrm{C}\left(\mathrm{u}_{\mathrm{o}}, \mathrm{v}_{\mathrm{o}}\right) \geq(\mathrm{n}-2) / 60$.

Theorem 4.2': $\mathrm{A}\left(\mathrm{C}, \mathrm{P}_{\mathrm{n}}\right) \geq(\mathrm{n}-2) / 60$.

We can now state the following conjectures:

Conjecture 4.1: Let $\mathrm{S}$ be a closed curve such that for any collection $\mathrm{P}_{\mathrm{n}}$ of points, there are $\mathrm{u}, \mathrm{v} \square \mathrm{P}_{\mathrm{n}}$ such that $\mathrm{S}(\mathrm{u}, \mathrm{v}) \geq \mathrm{n} \cdot \mathrm{c}, \mathrm{c}>0$. Then $\mathrm{S}$ is a circle. 
Conjecture 4.2: Let $S$ be a closed curve such that for any collection $P_{n}$ of points $A\left(S, P_{n}\right) \geq n \cdot c$, $c>0$. Then $\mathrm{S}$ is a circle.

At first glance, one might suspect that the results stated in Theorem 4.1' and 4.2' must hold for some curves $\mathrm{S}$ which are not circles. For instance if $\mathrm{E}[\mathrm{a}, \mathrm{b}]$ is an ellipse which is almost a circle, i.e. if $a / b=1-\square$ ( $\square$ sufficiently small, our intuition tells us that for any $P_{n}, A\left(E[a, b], P_{n}\right) \geq n \cdot c$, $c>0$. This, as we shall prove later, is not the case. In fact we will prove:

Theorem 4.10 [33]: Let $\mathrm{E}[\mathrm{a}, \mathrm{b}]$ be an ellipse which is not a circle. Then there are collections of points $P_{n}$ such that $A\left(E[a, b], P_{n}\right)=0$.

The following lemma, given without proof, will trivially imply Theorem 4.10.

Lemma 4.4 [33]: Let $\mathrm{E}=\mathrm{E}[\mathrm{a}, \mathrm{b}]$ be an ellipse which is not a circle, $\mathrm{u}, \mathrm{v}$ two points on a circle $\mathrm{C}$. Then there exists an ellipse $\mathrm{E}^{\prime} \square(\mathrm{E})$ such that $\mathrm{E}^{\prime} \square \mathrm{C}=\{\mathrm{u}, \mathrm{v}\}$.

Proof of Theorem 4.10: Let $\mathrm{P}_{\mathrm{n}}$ be any set of $\mathrm{n}$ points on a circle. By Lemma 4.4, for any $\mathrm{u}, \mathrm{v} \square \mathrm{P}_{\mathrm{n}}$, there exists $\mathrm{E}^{\prime} \square\left[(\mathrm{E})\right.$ such that $\mathrm{E}^{\prime} \square \mathrm{C}=\{\mathrm{u}, \mathrm{v}\}$. Then $\mathrm{E}(\mathrm{u}, \mathrm{v})=0$. This proves that $\mathrm{A}\left(\mathrm{E}, \mathrm{P}_{\mathrm{n}}\right)=0$.

Using techniques similar to the ones we used in Theorem 4.10, we can prove that $A\left(S, P_{n}\right)=0$ for the case when $\mathrm{S}$ is an $\mathrm{n}$-sided polygon. In fact, for all closed curves $\mathrm{S}$ we have analysed, we have always been able to prove that $\mathrm{A}\left(\mathrm{S}, \mathrm{P}_{\mathrm{n}}\right)=0$.

\section{TWO CHARACTERIZATIONS OF THE CIRCLE}

To finish this paper, we will present two characterizations of the circle. These results were motivated by the results previously obtained in this paper.

In Problem 3.1 we ask if crossing number 2 is a characterization of circle orders. A way to attack this problem is to determine first if there is another family of curves $\mathrm{F}$ homothetic to a closed curve $\mathrm{C}$ for which we could obtain, under a containment relation, partial orders with crossing number 2 . The reason why the crossing number of circle orders is at most two is a consequence of the following property:

P1: Any two different circles intersect in at most two points. 
It is thus natural to ask for the existence of another closed curve $\mathrm{C}$ for which the following property holds:

P2: Let $\mathrm{C}^{\prime}$ be any curve homothetic to $\mathrm{C}, \mathrm{C} \neq \mathrm{C}^{\prime}$. Then $\mathrm{C}$ intersects $\mathrm{C}^{\prime}$ in at most two points. We can now state our first characterization of the circle:

Theorem 5.1: Let $C$ be any curve that satisfies $P 2$, then $C$ is a circle.

Our second characterization is motivated by Lemma 4.1 and Conjecture 4.2. In Lemma 4.1 we prove that for any four points $\mathrm{u}, \mathrm{v}, \mathrm{x}, \mathrm{y}$ in the plane such that $\mathrm{l}(\mathrm{u}, \mathrm{v})$ and $\mathrm{l}(\mathrm{x}, \mathrm{y})$ intersect, any circle containing $\mathrm{u}$ and $\mathrm{v}$ contains at least one end point of $1(\mathrm{x}, \mathrm{y})$ or any circle containing $\mathrm{x}$ and $\mathrm{y}$ contains at least one end point of $\mathrm{l}(\mathrm{u}, \mathrm{v})$. It is not hard to prove that if Lemma 4.1 were true for a family of curves homothetic to a curve $\mathrm{C}$ not a circle, then Conjecture 4.2 would be false. Thus for Conjecture 4.2 to make any sense, we need to prove that Lemma 4.1 is indeed a characterization of the circle.

Theorem 5.2: Let $\mathrm{u}, \mathrm{v}, \mathrm{x}, \mathrm{y}$ be any four points in the plane such that $1(\mathrm{u}, \mathrm{v})$ and $1(\mathrm{x}, \mathrm{y})$ intersect. Let $\mathrm{F}$ be a family of curves homothetic to a curve $\mathrm{C}$ which satisfies: any element $\mathrm{C}^{\prime}$ of $\mathrm{F}$ containing $\mathrm{u}$ and $\mathrm{v}$ contains at least one end point of $1(\mathrm{x}, \mathrm{y})$ or any $\mathrm{C}^{\prime}$ in $\mathrm{F}$ containing $\mathrm{x}$ and $y$ contains at least one end point of $1(\mathrm{u}, \mathrm{v})$. Then $\mathrm{C}$ is a circle.

The proofs of these results will be given in a forthcoming paper.

\section{References}

[1] N. Alon and E. Scheinerman, Degrees of freedom versus dimension for containment orders, preprint (1987).

[2] I. Barany, J. Schmerl, S.J. Sidney and J. Urrutia, A combinatorial result on balls and points. To appear in Discrete and Computational Geometry.

[3] J. Blazek and N. Koman, A minimal problem concerning complete plane graphs, in: Theory of Graphs and its Applications, ed. M. Fiedler, Czechoslovak Academy of Sciences, Prague, (1964) 113-117.

[4] N. G. De Bruijn and P. Erdös, On a combinatorial problem, Indagationes Math. 10 (1948) 421-423.

[5] C. Carathéodory, Über den Variabilitätsbereich der Koeffizienten von Potenzreihen, die 
gegebene Werte nicht annehmen, Math. Ann. 64 (1907) 95-115.

[6] C. Carathéodory, Über den Variabilitätsbereich der Fourierschen Konstanten von positiven harmonischen Funktionen, Rend. Civc. Math. Palermo 32 (1911) 193-217.

[7] B.M. Chazelle, Optimal algorithms for computing depths and layers, Proc. 21th Allerton Conf. on Comm., Control and Computing, Monticello, (1983) 427-436.

[8] H. S. M. Coxeter, A problem of collinear points, Amer. Math. Monthly 55 (1948) 26-28.

[9] B. Dushnik and E. W. Miller, Partially ordered sets, Amer. J. Math. 63 (1941) 600-610.

[10] H. Edelsbrunner and M.H. Overrmars, On the equivalence of some rectangle problems, Information Processing Letters 14 (1982) 124-127.

[11] P. C. Fishburn, Interval Orders and Interval Graphs, A Study of Partially Ordered Sets , John Wiley \& Sons (1985).

[12] P. C. Fishburn, Interval orders and circle orders, preprint (1987).

[13] P. C. Fishburn and W. T. Trotter, Angle orders, Order 1 (1985) 333-343.

[14] M. C. Golumbic, Containment and intersection graphs, IBM Scientific Center T. R. 135 (1984).

[15] M.C. Golumbic, D. Rotem and J. Urrutia, Comparability graphs and intersection graphs, Discrete Math 43 (1983) 37-46.

[16] B. Grünbaum, Arrangements and spreads, Regional Conference Series in Mathematics 10. A. M. S.

[17] B. Grünbaum, Convex Polytopes, Interscience, London. 1967.

[18] R.H. Guting, O. Nurmi and T. Ottman, "The direct dominance problem", Proc.1st Symp. on Computational Geometry, Baltimore, (1985) 81-88.

[19] R. K. Guy, The decline and fall of Zarankiewie's theorem, in: Proof Techniques in Graph Theory, ed. F. Harary, Academic Press, New York (1969) 63-69.

[20] H. Hadwiger and H. Debrunner, Combinatorial Geometry in the Plane, tr. V. Klee, Holt, Reinhart and Winston (1964).

[21] R. Hayward, A note on the circle containment problem, To appear im Discrete and Computational Geometry.

[22] R. Hayward, D. Rappaport and R. Wegner, Some extremal results on circles containing 
points, To appear in Discrete and Computational Geometry.

[23] H.T. Kung, F. Luccio and F.P. Preparata, On finding the maxima of a set of vectors, J. of the ACM 22 (1975) 469-476.

[24] D.G. Kirkpatrick and R. Seidel, The ultimate planar convex hull algorithm?, SIAM J. on Computing 15 (1986) 287-299.

[25] D.G. Kirkpatrick and R. Seidel, Output-seize sensitive algorithms for finding maximal vectors, Proc.1 st Symp. on Computational Geometry, Baltimore (1985) 89-96.

[26] D.T. Lee and F.P. Preparata, An improved algorithm for the rectangle enclosure problem, J. of Algorithms 3 (1982) 218-224.

[27] V. Neumann-Lara and J. Urrutia, A combinatorial result on points and circles, To appear in Discrete Mathemetics (1987).

[28] F.P. Preparata and S.J. Hong, Convex hulls of finite sets of points in two and three dimensions, Communications of the ACM (1977) 87-93.

[29] F.P. Preparata and M.I. Shamos, Computational Geometry, Springer Verlag (1985).

[30] H.L. Royden, Real Analysis, 2nd ed., Macmillan (1968).

[31] J-R. Sack, N. Santoro and J. Urrutia, Containment of elementary geometric objects, Proc. 15th SE Conf. on Combinatorics, Graph Theory and Computing, Baton Rouge, (1984), 139-146.

[32] N. Santoro and J. Urrutia, Angle orders, regular n-gon orders and the crossing number of a partial order, T.R-87-09 University of Ottawa, (1987). Submitted to ORDER.

[33] N. Santoro and J. Urrutia, A combinatorial result on simple geometric figures containing points. In preparation.

[34] N. Santoro, J.B. Sidney, S.J. Sidney and J. Urrutia, Geometric containment and Pareto dominance, Theoretical Computer Science, to appear; preliminary version in Proc. 2nd Symp. on Theoretical Aspects of Computer Science, Saarbrucken (1985) 322-327.

[35] N. Santoro, J.B. Sidney, S.J. Sidney and J. Urrutia, Geometric containment and partial orders, School of Computer Science, Carleton University (1986).

[36] E. Scheinerman and J.C. Wierman, On circle containment orders, preprint (1987).

[37] J. Schmerl, Personal communication (1986).

[38] J. B. Sidney, S. J. Sidney and J. Urrutia, Circle orders, n-gon orders and the crossing 
number of partial orders, TR-87-01 University of Ottawa (1987). Submitted to ORDER.

[39] J. J. Sylvester, Problem 11,851, Math questions and solutions from the educational time, 59 (1893) 98-99.

[40] J. Urrutia, Circle order, regular n-gon order and the crossing number are comparability graph invariants. In preparation.

[41] V. Vaishnavi and D. Wood, Data strucures for rectangle containment and enclosure problems, Computer Graphics and Image processing 13 (1980) 372-384. 